\title{
Modification of a Ti-Mo alloy surface via plasma electrolytic oxidation in a solution containing calcium and phosphorus
}

\author{
Wojciech Simka a,*, Agnieszka Krząkała a , Danila M. Korotin ${ }^{b}$, Ivan S. Zhidkov ${ }^{c}$, Ernst Z. Kurmaev ${ }^{\mathrm{b}}$, \\ Seif O. Cholakh ${ }^{c}$, Karolina Kuna ${ }^{a}$, Grzegorz Dercz ${ }^{\text {, }}$, Joanna Michalska ${ }^{\text {e }}$, \\ Katarzyna Suchanek ${ }^{\mathrm{f}}$, Tadeusz Gorewoda ${ }^{\mathrm{g}}$
}

a Faculty of Chemistry, Silesian University of Technology, B. Krzywoustego Street 6, 44-100 Gliwice, Poland

${ }^{\mathrm{b}}$ Institute of Metal Physics, Russian Academy of Sciences-Ural Division, S. Kovalevskoi Street 18, 620990 Yekaterinburg, Russia

${ }^{c}$ Ural Federal University, Mira Street 9, 620002 Yekaterinburg, Russia

d Institute of Materials Science, University of Silesia, Bankowa Street 12, 40-007 Katowice, Poland

e Faculty of Materials Science and Metallurgy, Silesian University of Technology, Krasińskiego Street 8, 40-019 Katowice, Poland

${ }^{\mathrm{f}}$ The Henryk Niewodniczanski Institute of Nuclear Physics, Polish Academy of Sciences, Radzikowskiego Street 152, 31-342 Krakow, Poland

${ }^{\mathrm{g}}$ Institute of Non Ferrous Metals, Sowińskiego Street 5, 44-100 Gliwice, Poland

\section{A R T I C L E I N F O}

\section{Article history:}

Received 10 December 2012

Received in revised form 26 January 2013

Accepted 21 February 2013

Available online 4 March 2013

\section{Keywords:}

Ti-15Mo alloy

Vanadium-free alloy

Plasma electrolytic oxidation

Corrosion resistance

$\mathrm{Ca}$ and $\mathrm{P}$ incorporation

\begin{abstract}
A B S T R A C T
Investigations into the surface modification of a Ti-15Mo alloy via plasma electrolytic oxidation are reported. The oxidation process was conducted in a solution containing $\mathrm{Ca}\left(\mathrm{H}_{2} \mathrm{PO}_{2}\right)_{2}, \mathrm{H}_{3} \mathrm{PO}_{4}$, or $(\mathrm{HCOO})_{2} \mathrm{Ca}$. Anodisation was performed at voltages in the range of $100-400 \mathrm{~V}$. The morphology of the sample surface did not change during alloy oxidation at lower voltages. Higher voltages led to the incorporation of calcium and phosphorus or of calcium only into the formed oxide layer and to significant modification of the surface morphology. Based on the SEM and EDX analysis results, a set of samples was selected for further investigations. To study the surface of the Ti-Mo alloy after anodic oxidation, we used scanning electron microscopy (SEM), energy-dispersive X-ray spectroscopy (EDX), thin-layer X-ray diffraction (TLXRD), and X-ray photoelectron spectroscopy (XPS). The electrochemical characteristics of the modified alloy in Ringer's solution were determined. Anodisation results in a considerable increase in the corrosion resistance of the Ti-15Mo alloy.
\end{abstract}

(C) 2013 Elsevier Ltd. All rights reserved.

\section{Introduction}

The corrosion of metallic biomaterials is a serious problem. This corrosion leads to the degradation and release of implant materials, and the released ions can have a harmful effect on the organism. The most popular biomaterial is pure titanium or its alloy Ti-6Al-4V, which exhibits excellent properties for surgical applications, such as corrosion resistance. The high corrosion resistance of pure titanium is due to the spontaneous formation of a protective oxide layer $\left(\mathrm{TiO}_{2}\right)$ on its surface. This layer also forms on the titanium alloy surface. The addition of alloying elements to titanium (e.g., Al and V) improves titanium's mechanical properties. However, it is possible for the ions to be released and to have a toxic effect on the human organism; thus, it is important to avoid such elements [1-6]. These elements can be replaced by nontoxic elements, such as $\mathrm{Zr}, \mathrm{Nb}, \mathrm{Ta}$, or Mo [5], although the mechanical and microstructural properties of the alloys change due to this replacement. Molybdenum is

\footnotetext{
* Corresponding author.

E-mail address: wojciech.simka@polsl.pl (W. Simka).
}

considered a safe alloying element and an excellent $\beta$-phase stabiliser. Increasing the amount of the $\beta$-phase leads to a decrease in the elastic modulus, an increase in the corrosion resistance and an improvement in the tissue response of Ti alloys [7-9]. Ti-Mo alloys exhibit low yield strength and good ductility, and they are more suitable for biomedical applications than conventional biomaterials because of their better mechanical compatibility. However, the mechanical properties are not the only factors that determine the quality of the implant.

Hydroxyapatite $\mathrm{Ca}_{10}\left(\mathrm{PO}_{4}\right)_{6}(\mathrm{OH})_{2}(\mathrm{HA})$ has excellent biocompatibility and bioactivity [10] but cannot be used as a medical implant because of its poor mechanical properties [11]. HA is therefore used as a coating material on metallic implants, such as those made of titanium and its alloys [12]. Among the different methods developed to form HA or HA-type coatings on $\mathrm{Ti}$ and its alloys, the hydrothermal method [13] and anodic oxidation [14] are the most common methods used. Surface characterisation is very important to ensure a reasonable growth rate and good adhesion of HA to the titanium surface. PEO (plasma electrochemical oxidation) is a relatively inexpensive and simple process that leads to increased surface roughness $[15,16]$. The surface intrusions should have a 
Table 1

The chemical composition of anodising baths.

\begin{tabular}{llll}
\hline Bath & \multicolumn{2}{l}{ Component, mol dm } \\
\cline { 2 - 4 } & $\mathrm{Ca}\left(\mathrm{H}_{2} \mathrm{PO}_{2}\right)_{2}$ & $(\mathrm{HCOO})_{2} \mathrm{Ca}$ & $\mathrm{H}_{3} \mathrm{PO}_{4}$ \\
\hline $\mathrm{A}$ & 1.0 & - & - \\
$\mathrm{B}$ & 0.1 & - & - \\
$\mathrm{C}$ & 0.1 & - & 0.1 \\
$\mathrm{D}$ & - & 1.0 & - \\
E & - & 0.1 & - \\
\hline
\end{tabular}

size that is suitable for cell penetration - typically on the order of $100 \mu \mathrm{m}$. Pore sizes larger than $100 \mu \mathrm{m}$ are necessary to promote the ingrowth of bone tissue in an implant [17]. PEO allows the synthesis of ceramic-like oxide films on some metals. The PEO process combines electrochemical oxidation with a high-voltage spark treatment in aqueous electrolytic baths $[18,19]$. The coatings usually contain amorphous and crystalline phases (in the case of titanium rutile and anatase), and some constituents can be incorporated from the electrolyte $[15,16,20,21]$. In the electrolyte, chemical compounds that facilitate bone growth are usually used, such as compounds containing phosphorous and calcium (which include hydroxyapatite $\mathrm{HA}$ ) and silicon oxide.

The aim of this work was to obtain an oxide layer containing calcium and phosphorous ions on the surface of a Ti-15Mo alloy via plasma electrochemical oxidation (PEO). The influence of the PEO parameters on the morphology and chemical composition of the layer were determined. Additionally, the electrochemical characteristics of the modified alloy in physiological Ringer's solution were determined.

\section{Experimental}

The composition of the Ti-15Mo (BIMO Metals, Wrocław, Poland) alloy used in this investigation was as follows: 14.73-14.98 wt.\% Mo, 0.016 wt.\% N, 0.06 wt.\% Fe, 0.008 wt.\% C, $0.001 \mathrm{wt} . \% \mathrm{H}, 0.15 \mathrm{wt} . \% \mathrm{O}$, and the balance Ti. The pretreatment of the samples was conducted as follows: polishing with a 600 granulation abrasive paper, etching in a solution containing $\mathrm{H}_{2} \mathrm{SO}_{4}$ $\left(4 \mathrm{~mol} \mathrm{dm}^{-3}\right)$ and $\mathrm{HF}\left(1 \mathrm{~mol} \mathrm{dm}^{-3}\right)$ for $1 \mathrm{~min}$, rinsing in deionised water, and cleaning ultrasonically for $5 \mathrm{~min}$. Anodisation was conducted at a current density of $0.1 \mathrm{Adm}^{-2}$ for $5 \mathrm{~min}$. The chemical compositions of the baths are listed in Table 1 . The sample labels and treatment conditions are listed in Table 2. After anodisation, the samples were rinsed with deionised water and ultrasonically cleaned with 2-propanol and deionised water. For the anodisation, a DC power supply (PWR800H, Kikusui, Japan) was used.

The morphology and chemical composition of the anodic layer formed on the surface were determined, and a cross-sectional analysis was conducted using a scanning electron microscope (SEM, Hitachi S-3400N, accelerating voltage of $25 \mathrm{kV}$ ) with an energydispersive X-ray spectrometer (EDX, Thermo Noran).

The X-ray diffraction measurements were performed on an XPert Philips PW 3040/60 diffractometer operating at $30 \mathrm{~mA}$ and $40 \mathrm{kV}$, which was equipped with a vertical goniometer and an Eulerian cradle. The radiation wavelength $\left(\lambda \mathrm{Cu}_{\mathrm{K} \alpha}\right)$ was $1.54178 \AA$. Grazing incidence X-ray diffraction (GIXD) patterns were taken over the $2 \theta$ range of $10^{\circ}-80^{\circ}$ with a $0.05^{\circ}$ step at an incident angle $\alpha$ of $0.25^{\circ}[22,23]$.

The XPS measurements were conducted using a high spatialand energy-resolution PHI XPS Versaprobe 5000 spectrometer (ULVAC-Physical Electronics, USA, 2011). This spectrometer uses a classic X-ray optical scheme with a spherical quartz monochromator and an energy analyser that works in the binding energy range of $0-1500 \mathrm{eV}$ and has an electrostatic focusing system and magnetic screening. The energy resolution was $\Delta E \sim 0.5 \mathrm{eV}$ with an $\mathrm{Al} \mathrm{K \alpha}$ source, and the spot size was $200 \mu \mathrm{m}$. A dual-channel neutraliser was used to compensate for the local charging of the studied sample that occurred due to photoelectron loss. All studied samples were kept in the vacuum chamber for $24 \mathrm{~h}$ under rotary pumping and were measured at a pressure of $10^{-7} \mathrm{~Pa}$. Typical signal-to-noise ratios were at least 5000 . The spectra were processed using the ULVAC-PHI MultiPak 9.2 software, and the residual background was removed using the Tougard method. The XPS spectra were calibrated relative to the reference energy of the carbon $1 \mathrm{~s}$ core-level at $284.5 \mathrm{eV}$.

The XRF analysis was conducted using a ZSX Primus X-ray fluorescence spectrometer (Rigaku) equipped with an $\mathrm{Rh}$ tube and with the equipment necessary for surface preparation. The instrument is equipped with secondary radiation masks with the following dimensions: $0.5,1,10,20,30$, and $35 \mathrm{~mm}$ (for this study, we only used the $10 \mathrm{~mm}$ mask). The instrument is also equipped with a scintillation counter (SC) and a flow proportional counter (PC). A semi-quantitative XRF analysis was performed using a set of UniQuant (Omega Data System NL) reference materials.

All Raman spectra were acquired using a high-resolution Nicolet Almega XR Thermo Electron Corp. system equipped with a $50 \mathrm{~mW}$, $532 \mathrm{~nm}$, frequency-doubled NdYAG laser as an excitation source. The laser beam was focused through the $100 \times$ objective of an Olympus BX41 microscope to a $1 \mu \mathrm{m}$ spot size. The scattered light was collected in the backscattering geometry using a thermoelectrically cooled CCD detector. A spectral resolution of $2 \mathrm{~cm}^{-1}$ was achieved by the system.

The roughness (Ra parameter) of the samples was measured using a Mitutoyo Surftest SJ-301 profilometer according to the EN ISO 4287:1997 standard [24]. The Ra parameter is the arithmetic mean of the roughness profile values:

$R a=\frac{1}{l} \int_{0}^{l}|Z(x)| \mathrm{d} x$

where $|Z(x)|$ is the absolute ordinate value inside the elementary measuring length and $l$ is the elementary length in the $x$ direction (average line) used to determine the unevenness of the studied characterising profile.

The corrosion resistance of the Ti-15Mo alloy samples was investigated in Ringer's simulated body fluid, which was composed of $8.6 \mathrm{~g} \mathrm{dm}^{-3} \mathrm{NaCl}, 0.3 \mathrm{~g} \mathrm{dm}^{-3} \mathrm{KCl}$, and $0.48 \mathrm{~g} \mathrm{dm}^{-3} \mathrm{CaCl}_{2} \cdot 6 \mathrm{H}_{2} \mathrm{O}$ (Baxter, USA). The apparatus used for this investigation was a standard two-chamber electrochemical experimental cell with three electrodes inside the cell: a working electrode, a platinum auxiliary electrode, and a Haber-Luggin capillary with a reference electrode (saturated calomel electrode - SCE). The electrochemical behaviour of the investigated titanium alloy samples was examined using an AUTOLAB computer-controlled potentiostat (model PGSTAT 30 with the GPES computer program. The investigation included the following:

(a) recording the open-circuit potential $E_{\mathrm{OCP}}$ as a function of time,

(b) determining the $\log j=f(E)$ curve for potentials ranging from $E_{\mathrm{OCP}}-200 \mathrm{mV}$ to $E_{\mathrm{OCP}}+200 \mathrm{mV}$ (potential sweep rate $-2 \mathrm{mV} \mathrm{s}^{-1}$ ), and based on this curve, determining the following:

(i) the corrosion potential $E_{\mathrm{CORR}}$, in $\mathrm{mV}$,

(ii) the corrosion current density $j_{\mathrm{CORR}}$, in $\mathrm{A} \mathrm{cm}^{-2}$, and

(iii) the polarisation resistance $\mathrm{Rp}$, in $\Omega \mathrm{cm}^{2}$,

(c) recording the voltammetric curve $(\mathrm{CV})$ for potentials ranging from -0.5 to $3 \mathrm{~V}\left(\mathrm{~d} E \mathrm{~d} t^{-1}=100 \mathrm{mV} \mathrm{s}^{-1}\right)$. 
Table 2

The sample labels, anodizing voltage, EDX chemical analysis of the surface samples, and calculated based on the EDX analysis Ti/Ca and Ti/P ratios.

\begin{tabular}{|c|c|c|c|c|c|}
\hline Sample & Bath & Anodising voltage, $\mathrm{V}$ & EDX analysis & $\mathrm{Ti} / \mathrm{Ca}$ atomic ratio & $\mathrm{Ti} / \mathrm{P}$ atomic ratio \\
\hline AMo1 & A & 100 & Ca, P, Mo, O, Ti & 178.1 & 42.4 \\
\hline AMo2 & & 200 & Ca, P, Mo, O, Ti & 6.7 & 2.2 \\
\hline AMo3 & & 300 & Ca, P, Mo, O, Ti & 2.1 & 1.1 \\
\hline AMo4 & & 400 & Ca, P, Mo, O, Ti & 1.1 & 0.8 \\
\hline BMo1 & B & 100 & Mo, O, Ti & - & - \\
\hline BMo2 & & 200 & P, Mo, O, Ti & - & 27.1 \\
\hline BMO3 & & 300 & Ca, P, Mo, O, Ti & 22.9 & 2.7 \\
\hline BMo4 & & 400 & Ca, P, Mo, O, Ti & 9.7 & 2.0 \\
\hline CMo1 & C & 100 & P, Mo, O, Ti & - & 64.9 \\
\hline CMo2 & & 200 & P, Mo, O, Ti & - & 20.1 \\
\hline CMo3 & & 300 & Ca, P, Mo, O, Ti & 10.5 & 2.4 \\
\hline CMo4 & & 400 & $\mathrm{Ca}, \mathrm{P}, \mathrm{Mo}, \mathrm{O}, \mathrm{Ti}$ & 3.6 & 1.5 \\
\hline DMo1 & $\mathrm{D}$ & 100 & Mo, O, Ti & - & - \\
\hline DMo2 & & 200 & Ca, Mo, O, Ti & 3.9 & - \\
\hline DMo3 & & 250 & Ca, Mo, O, Ti & 2.3 & - \\
\hline EMo1 & E & 100 & Mo, O, Ti & - & - \\
\hline EMo2 & & 200 & Ca, Mo, O, Ti & 9.2 & - \\
\hline EMo3 & & 250 & Ca, Mo, O, Ti & 8.7 & - \\
\hline
\end{tabular}

\section{Results and discussion}

\subsection{Preliminary investigations}

The results indicate that the morphology and chemical composition of the obtained layers strongly depend on the voltage applied during the PEO process and on the chemical composition of the baths used. In Fig. 1, the SEM image of the AMo1 sample anodised in a $\mathrm{Ca}\left(\mathrm{H}_{2} \mathrm{PO}_{2}\right)_{2}$ solution at $100 \mathrm{~V}$ is shown. The surface of this sample is compact and slightly different from those of typical etched titanium alloy samples [25]. The EDX analysis indicated that, besides the substrate alloy elements (Ti, Mo), small amounts of $\mathrm{Ca}$ and $\mathrm{P}$ were incorporated into the surface layer. The Ti/Ca and Ti/P atomic ratios are equal to 178.1 and 42.4, respectively (Table 2 ). In Fig. 1, the images of the AMo2, AMo3, and AMo4 samples are also shown. It is clear that an increase in the applied voltage changes the surface microstructure. For higher voltages, the samples are more varied with small holes that are characteristic of PEO; the pore diameters are between 0.694 and $3.1 \mu \mathrm{m}$ (AMo2 sample) or 0.635 and $4.39 \mu \mathrm{m}$ (AMo4 sample) (Table 3) [17,19]. However, an increase in the voltage also causes more cracks in the surface. The EDX analysis indicated the presence of $\mathrm{Ca}$ and $\mathrm{P}$ on the surface of the anodised samples (Table 2). The largest amounts of these elements were obtained when the sample was anodised at $300 \mathrm{~V}$ (atomic ratio Ti/Ca: 2.1 ; Ti/P: 1.1 ). When a $400 \mathrm{~V}$ voltage was applied, the increase in the amounts of $\mathrm{Ca}$ and $\mathrm{P}$ was not significant (atomic ratio $\mathrm{Ti} / \mathrm{Ca}$ : 1.1 ; Ti/P: 0.8 ). When a $200 \mathrm{~V}$ voltage was applied, the decrease in the $\mathrm{Ca}$ and $\mathrm{P}$ content in the surface layer was also not substantial.

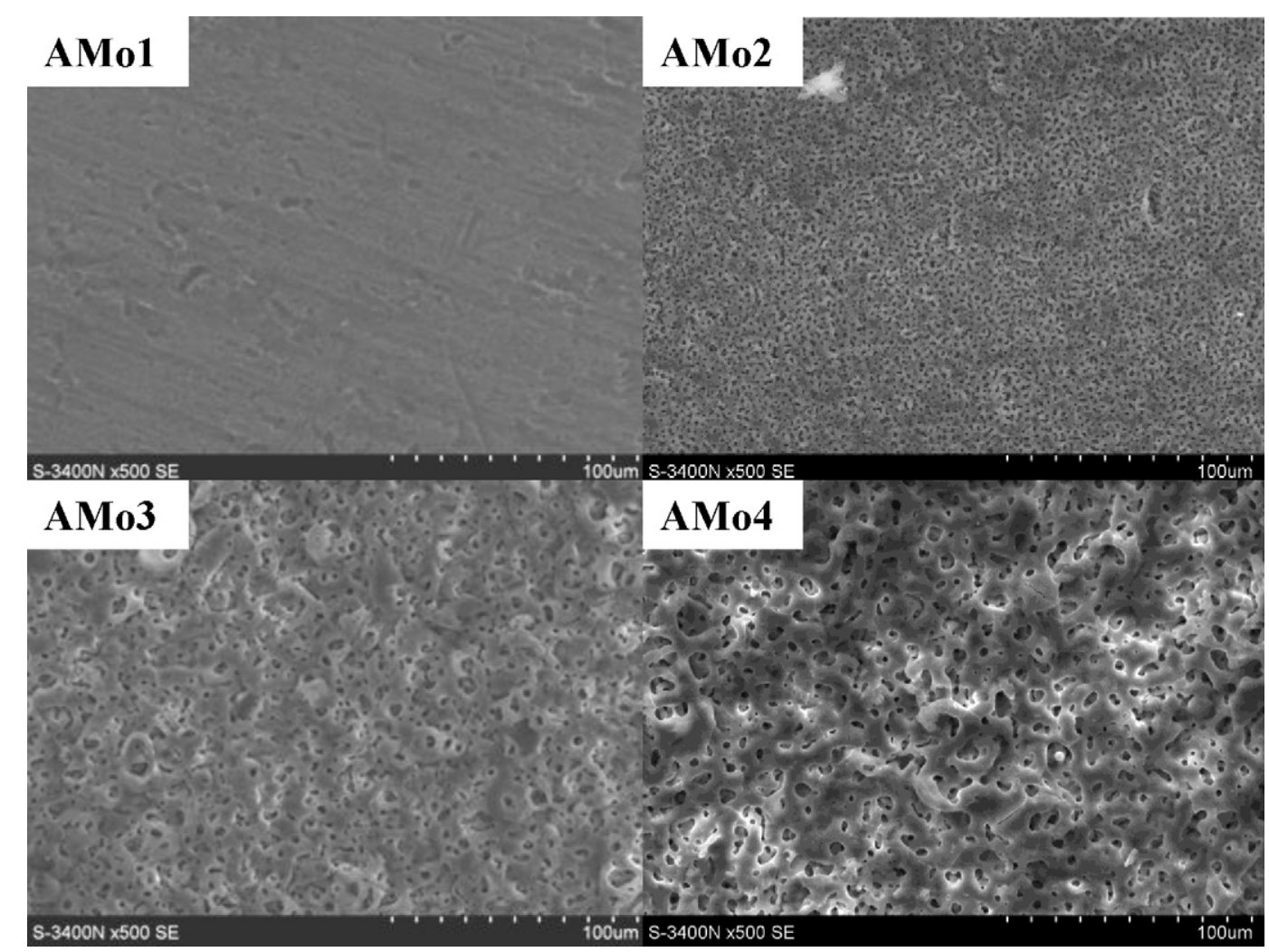

Fig. 1. The SEM images of Ti-15Mo alloy samples after anodising in A bath at different voltages (AMo1 - 100 V, AMo2 - 200 V, AMo3 - 300 V, AMo4 - 400 V). 


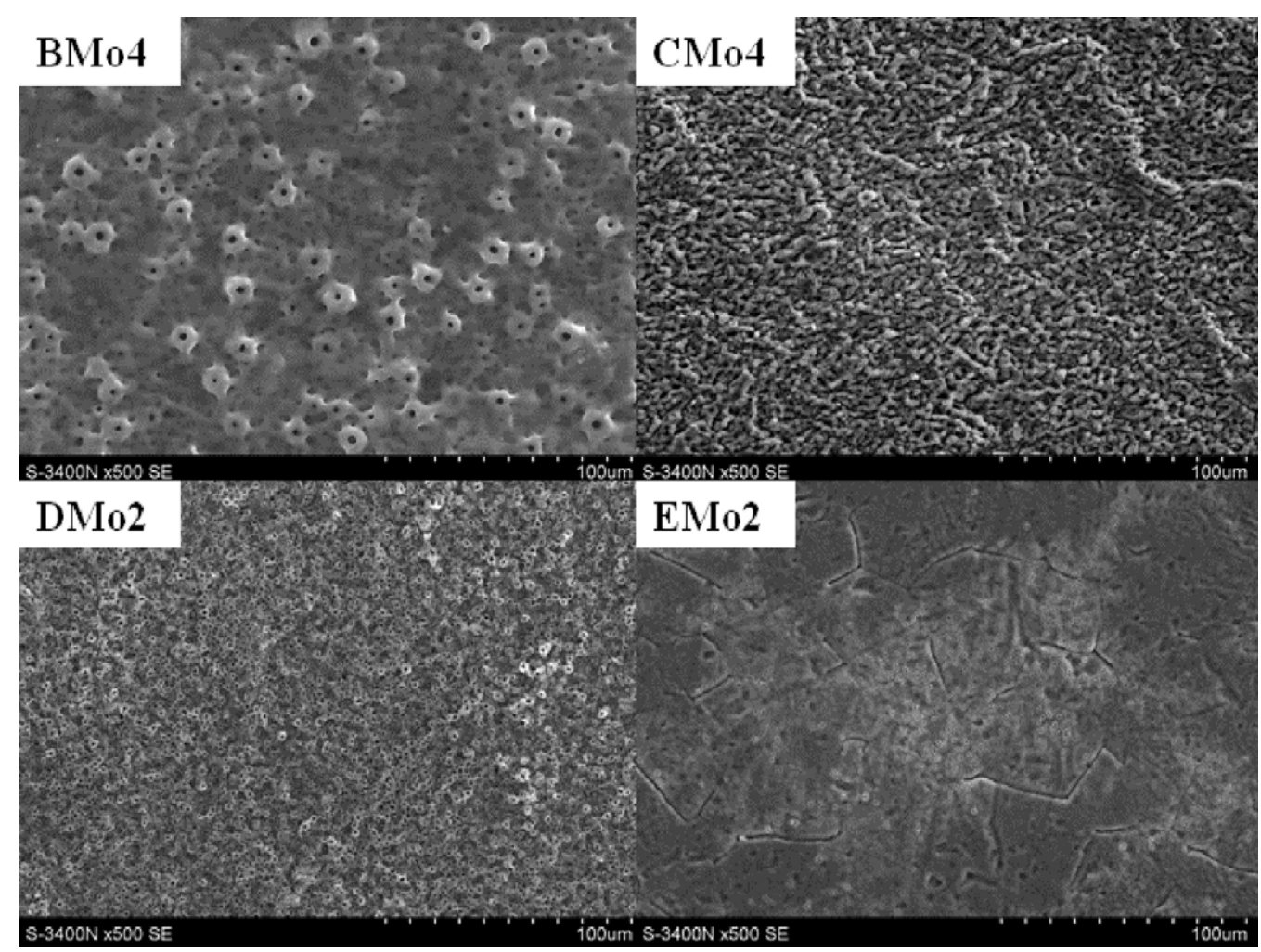

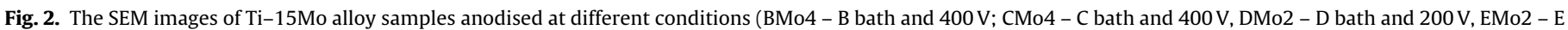
bath and $200 \mathrm{~V})$.

The surface microstructures of the samples treated in the B and C baths show similar dependencies (all of the sample surfaces are not shown). There was only a difference in layer composition, in comparison to samples anodised in the A bath, when a lower voltage was applied, i.e., 100 or $200 \mathrm{~V}$; calcium was not incorporated into the surface layer (Table 2). Samples anodised in the D bath were porous, which is characteristic of PEO, and the calcium was incorporated when the voltage was 200 and $250 \mathrm{~V}$ (Fig. 2 and Table 2). The sample surface anodised at $100 \mathrm{~V}$ was compact, and a higher voltage (200 and $250 \mathrm{~V}$ ) caused a more porous surface. The EDX analysis indicates that Ca was not incorporated into the layer when a voltage $100 \mathrm{~V}$ was applied. Based on the SEM and EDX analysis results, a set of samples was selected for further investigations. The set of samples included the following: AMo2, BMo4, CMo4, DMo2, and EMo2. For these samples, more detailed examinations, including XRF, XRD, XPS, Raman spectroscopy, cross-sectional analysis, surface profiling, and corrosion investigations, were performed.

\subsection{Surface investigations of selected samples}

A porous and rough surface layer can be obtained via PEO using suitable conditions (voltage and bath composition). The results of

Table 3

The roughness, diameter of micropores, and thickness of surface layer of selected Ti-15Mo alloy samples.

\begin{tabular}{lccc}
\hline Sample & Ra, $\mu \mathrm{m}$ & $\begin{array}{l}\text { Diameter of } \\
\text { micropores, } \mu \mathrm{m}\end{array}$ & $\begin{array}{l}\text { Thickness of } \\
\text { surface layer, } \mu \mathrm{m}\end{array}$ \\
\hline Ti-15Mo & 0.39 & - & - \\
AMo2 & 0.37 & $0.694-3.10$ & $2.70-3.77$ \\
BMo4 & 1.18 & $0.627-2.84$ & $2.94-4.09$ \\
CMo4 & 0.64 & $1.79-4.47$ & $6.07-7.38$ \\
DMo2 & 0.52 & $0.825-1.90$ & $3.45-5.56$ \\
EMo2 & 0.47 & $0.577-1.48$ & $0.54-0.75$ \\
\hline
\end{tabular}

the roughness investigations are presented in Table 3 . The obtained Ra factor is highest $(1.18 \mu \mathrm{m})$ for the BMo4 sample anodised in the bath containing $0.1 \mathrm{M} \mathrm{Ca}\left(\mathrm{H}_{2} \mathrm{PO}_{2}\right)_{2}$ at $400 \mathrm{~V}$. The addition of $0.1 \mathrm{M} \mathrm{H}_{3} \mathrm{PO}_{4}$ caused the Ra factor to decrease to $0.64 \mu \mathrm{m}$. The porosity of the surface layer anodised in the A bath does not differ from that of the sample that was only etched; the Ra factors are 0.37 and $0.39 \mu \mathrm{m}$. The obtained roughness is similar for the samples anodised in the $\mathrm{D}$ and $\mathrm{E}$ baths (which differ from each other only in the concentration of $\left.(\mathrm{HCOO})_{2} \mathrm{Ca}\right)$, and the Ra factors are 0.52 and $0.47 \mu \mathrm{m}$. The pore diameters vary from 0.577 to $4.47 \mu \mathrm{m}$ depending on the applied voltage and the type of bath (Table 3). Additionally, the thicknesses of the obtained layers were different $(0.54-7.34 \mu \mathrm{m})$. The thinnest layers were obtained using bath $C$ at $400 \mathrm{~V}$ (Table 3). Generally, the thicknesses of the layers depend on the applied voltage and decrease with decreasing voltage. In Fig. 3, the exemplary cross-section SEM image and the EDX analysis of the AMo2 sample are shown, indicating a barrier-type coating layer [26]. The same barrier layer was observed in all of the examined samples. The growth of an oxide layer via plasma electrolytic oxidation, local breakdown using a small spark, and the subsequent oxygen gas evolution resulted in the formation of this complicated structure $[27,28]$. The thicknesses of the obtained layers also depend on the electrolyte concentration. The obtained coatings were significantly thicker when higher concentrations of $(\mathrm{HCOO})_{2}$ Ca were used.

\subsection{Chemical and phase analysis of selected sample surfaces}

Surface modification of metallic implants is necessary to facilitate the formation of connections between an implant material and tissue. Both the presence of compounds containing $\mathrm{Ca}$ and $\mathrm{P}$ and their chemical form are important for bone growth [29-32]. A detailed chemical analysis of selected samples was conducted using different analytical techniques. The results of the XRF analysis are 

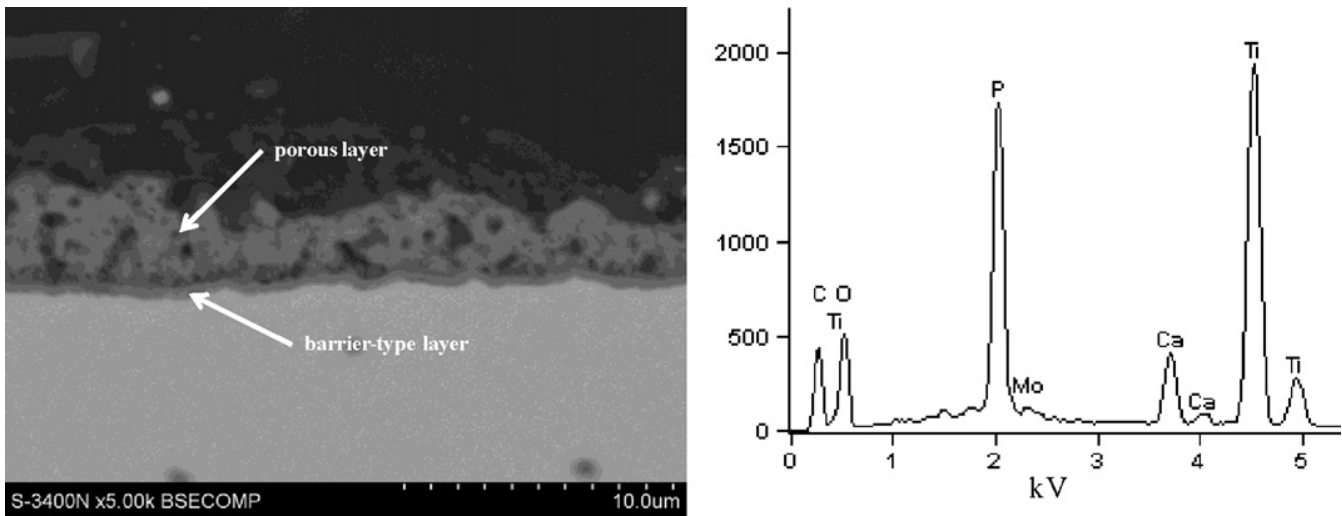

Fig. 3. The cross-section and EXD spectra of AMo2 sample (anodized in A bath at $200 \mathrm{~V}$ ).

Table 4

The XRF analysis of selected Ti-15Mo alloy samples.

\begin{tabular}{llllll}
\hline Sample & \multicolumn{5}{l}{ Element, at.\% } \\
\cline { 2 - 6 } & $\mathrm{Ti}$ & Mo & $\mathrm{P}$ & $\mathrm{Ca}$ & $\mathrm{O}$ \\
\hline AMo2 & 40.7 & 9.9 & 7.6 & 3.9 & 37.8 \\
BMo4 & 38.6 & 9.2 & 7.9 & 1.6 & 42.7 \\
CMo4 & 44.0 & 10.3 & 7.6 & 1.8 & 36.4 \\
DMo2 & 52.6 & 12.79 & & 4.89 & 29.6 \\
EMo2 & 52.0 & 12.5 & & 0.02 & 35.5 \\
\hline
\end{tabular}

presented in Table 4. The XRF analysis showed the presence of alloy elements ( $\mathrm{Ti}$ and $\mathrm{Mo}$ ) and of oxygen, indicating the oxidation of the sample. In the case of the $\mathrm{A}, \mathrm{B}$, and $\mathrm{C}$ samples, the incorporation of $\mathrm{Ca}$ and $\mathrm{P}$ was confirmed, and only Ca was incorporated into the $\mathrm{D}$ and $\mathrm{E}$ samples. The amount of incorporated phosphorous was similar (for samples A, B, and C), 7.6-7.9 at.\%, despite the use of different voltages and different concentrations of $\mathrm{Ca}\left(\mathrm{H}_{2} \mathrm{PO}_{2}\right)_{2}$. It could be expected that more $\mathrm{P}$ ions will be incorporated into the oxide layers with increasing voltages and increasing concentrations of the phosphates in the electrolyte. The concentration of Ca was highest in the surface layer of the AMo2 sample, 3.9 at.\%, because the concentration of $\mathrm{Ca}\left(\mathrm{H}_{2} \mathrm{PO}_{2}\right)_{2}$ was the highest in the A electrolyte, and the amount of incorporated Ca decreased with decreasing concentration. For the $\mathrm{BMo} 2$ and $\mathrm{CMo} 2$ samples, the amount of Ca was similar, varying from 1.6 to 1.8 at.\%. The addition of $\mathrm{H}_{3} \mathrm{PO}_{4}$ had no

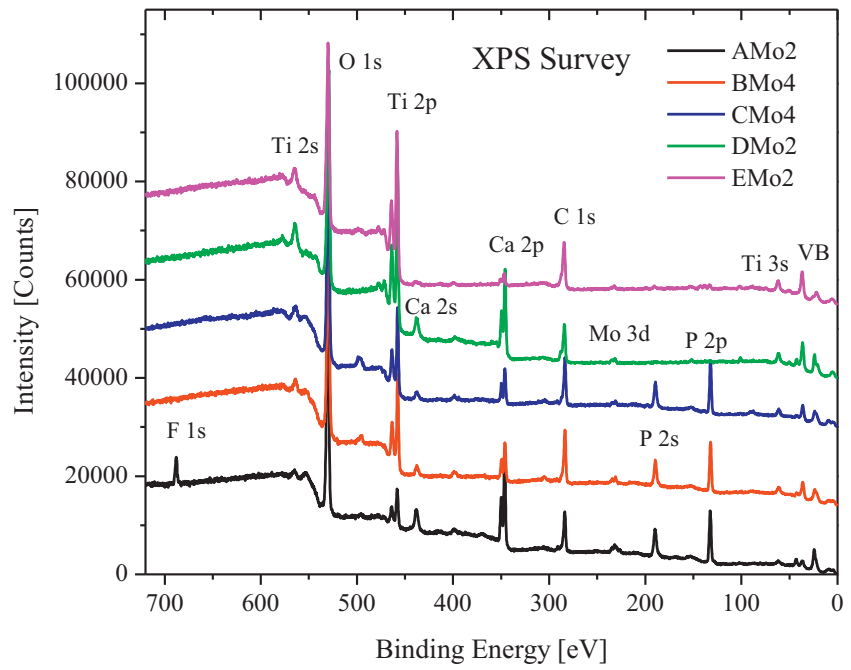

Fig. 4. The XPS survey spectra $(0-750 \mathrm{eV})$ of Ti-Mo alloy samples after anodic oxidation (AMo2 - A bath and 200 V, BMo4 - B bath and 400 V; CMo4 - C bath and $400 \mathrm{~V}, \mathrm{DMo} 2$ - D bath and 200 V, EMo2 - E bath and 200 V). effect on the amount of incorporated $\mathrm{P}$. In the case of the $\mathrm{D}$ and $\mathrm{E}$ samples, the concentration of $(\mathrm{HCOO})_{2} \mathrm{Ca}$ in the electrolyte influenced the amount of Ca in the surface layer, which was 4.89 at.\% (DMo2 sample) and 0.02 at.\% (EMo2 sample). The lower concentration of $\mathrm{Ca}$ in the sample EMo2 is at least partly due to the much smaller thickness of the anodic layer on that sample (Table 4). The measured composition depends not only on the real composition of the anodic layer but also on its thickness. If the thickness of the anodic layer is much smaller than the depth of analysis, the results of the XRF measurements do not reflect the composition of the layer, but the composition measured by XRF will be the weighted average of the composition of the layer and the substrate (but the weighting factor is not easy to calculate).

The XPS survey spectra of the Ti-Mo alloys after anodic oxidation are shown in Fig. 4. The obtained results are in good agreement with the EDX and XRF data. Additional (to the Ti and Mo signals from the host material) calcium and phosphorus signals are detected in the AMo2, BMo4, and CMo4 samples anodised in $\mathrm{Ca}\left(\mathrm{H}_{2} \mathrm{PO}_{2}\right)_{2}$ and $\mathrm{H}_{3} \mathrm{PO}_{4}$ solutions, whereas only additional $\mathrm{Ca}$ signals are observed for the DMo2 and EMo2 samples anodised in the ( $\mathrm{HCOO})_{2} \mathrm{Ca}$ solution (Table 1). The relative ratios of the Ti, Mo, and $\mathrm{O}$ signals also agree with the results of the XRF analysis. The chemical states of the constituent atoms can be estimated from the XPS measurements of the valence band (VB) and core levels. The XPS valence band spectra (Fig. 5) show that the semi-core Ca 3p- and O 2s-states

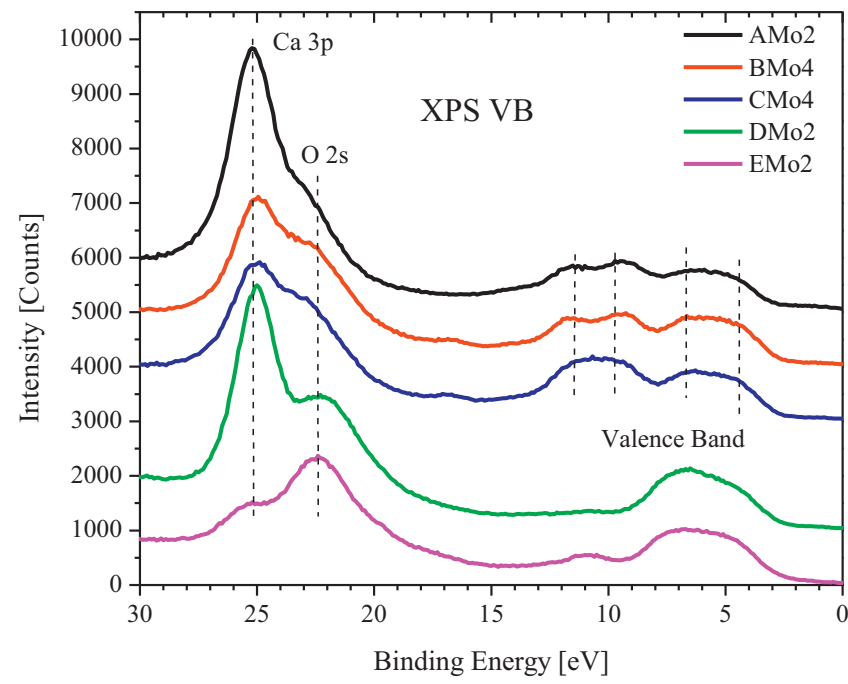

Fig. 5. The XPS spectra of Ti-Mo alloy samples at energy range of $0-30 \mathrm{eV}$ (AMo2 - A bath and $200 \mathrm{~V}, \mathrm{BMo} 4-\mathrm{B}$ bath and $400 \mathrm{~V}$; CMo4 - C bath and 400 V, DMo2 - D bath and $200 \mathrm{~V}, \mathrm{EMo} 2-\mathrm{E}$ bath and $200 \mathrm{~V}$ ). 


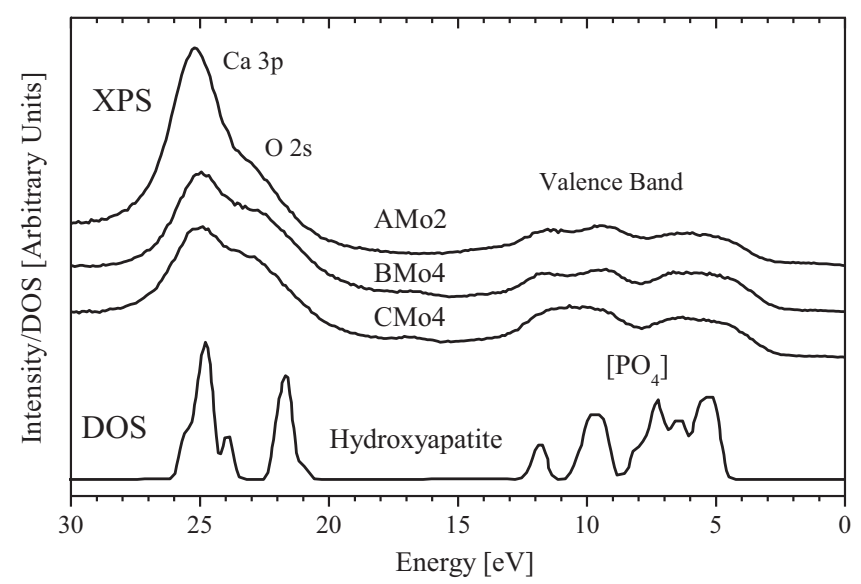

Fig. 6. Comparison of XPS spectra of AMo2, BMo4, and CMo4 samples with electronic structure calculations of hydroxyapatite (HA).

are located in the energy range from 18 to $28 \mathrm{eV}$. The valence band structure at $0-12 \mathrm{eV}$ is different for the AMo2, BMo4, CMo4, DMo2, and EMo2 samples. For the first series of Ti-Mo samples (AMo2, BMo4, and CMo4), this valence band has a complicated four-peak structure that is very close to the calculated total density of states of hydroxyapatite (Fig. 6) [33], whereas the XPS VB of the DMo2 and EMo2 samples is similar to that of $\mathrm{TiO}_{2}$ (Fig. 5). According to these calculations, the valence bands mainly consist of the $\mathrm{P}$ and $\mathrm{O}$ states binding the $\mathrm{PO}_{4}$ groups, with some contribution from the Ca states to the bottom of the lower bands. Therefore, we can conclude that $\left[\mathrm{PO}_{4}\right]^{-}$is incorporated into the surface oxide layer of these samples (AMo2, BMo4, and $\mathrm{CMo} 4$ ) during anodic oxidation of the Ti-15Mo alloy in $\mathrm{Ca}\left(\mathrm{H}_{2} \mathrm{PO}_{2}\right)_{2}$ and $\mathrm{H}_{3} \mathrm{PO}_{4}$ solutions. This conclusion is confirmed by XPS measurements of the $\mathrm{P} 2 \mathrm{p}$-core levels of the anodised alloys (Fig. 7). A strong P 2p single peak at a binding energy of $133.4 \mathrm{eV}$ was detected for all of the samples, which can clearly be assigned to phosphate-type species [34]. This conclusion is also in accordance with measurements of the XPS O 1s spectra (Fig. 8), where the peak has a binding energy of approximately 530.9-531.1 eV for AMo2, BMo4, and CMo4 samples, similar to hydroxyapatite [35]. The DMo2 and EMo2 samples have the $O$ 1 s peak at 530.3-530.4 eV, which is typical for $\mathrm{O}^{2-}$ species (Fig. 8). The XPS Ca 2p and Ti 2p spectra of the Ti-Mo alloy samples after anodic oxidation shown in Fig. 9 show that Ca 2p binding energies are the same in all samples and close to that of $\mathrm{Ca}^{2+}$. The XPS Ti 2p spectra show that in all samples, Ti has an oxidation state of $\mathrm{Ti}^{4+}$. Based on a comparison of the XPS survey spectra of $\mathrm{CaTiO}_{3}$ with DMo2 and EMo2 samples, we can conclude that $\mathrm{Ca}$ is present in the form of calcium titanate (Fig. 10) [37].

The chemical state of the Mo atoms can be estimated from the XPS Mo 3d measurements (Fig. 11). These results show that the Mo atoms exhibit a mixture of the (4+) and (5+) oxidation states for BMo4 and CMo4 [36]. For DMo2 and EMo2, the Mo atoms have $(4+),(5+)$, and $\left(6^{+}\right)$oxidation states [36]. In the case of AMo2, (3+), $(4+)$, and $(5+)$ states [36] occur.

Fig. 12 shows the presence of an As signal on the surface of the Ti-15Mo alloy after etching it in $4 \mathrm{M} \mathrm{H}_{2} \mathrm{SO}_{4}+1 \mathrm{M} \mathrm{HF}$ and anodising it (for the AMo2, BMo4, CMo4, and DMo2 samples). This signal can be explained by the contamination of the hydrofluoric acid with arsenic trifluoride [38] during the production of the HF via treatment of the mineral fluorite $\left(\mathrm{CaF}_{2}\right)$ with concentrated sulphuric acid $\left(\mathrm{H}_{2} \mathrm{SO}_{4}\right)$. Arsenic is naturally present in $\mathrm{CaF}_{2}$ in the trivalent As-III state and is impossible to completely remove [39], which can explain why traces of As are present even in the purest commercially available hydrofluoric acid [40]. We observed a similar result

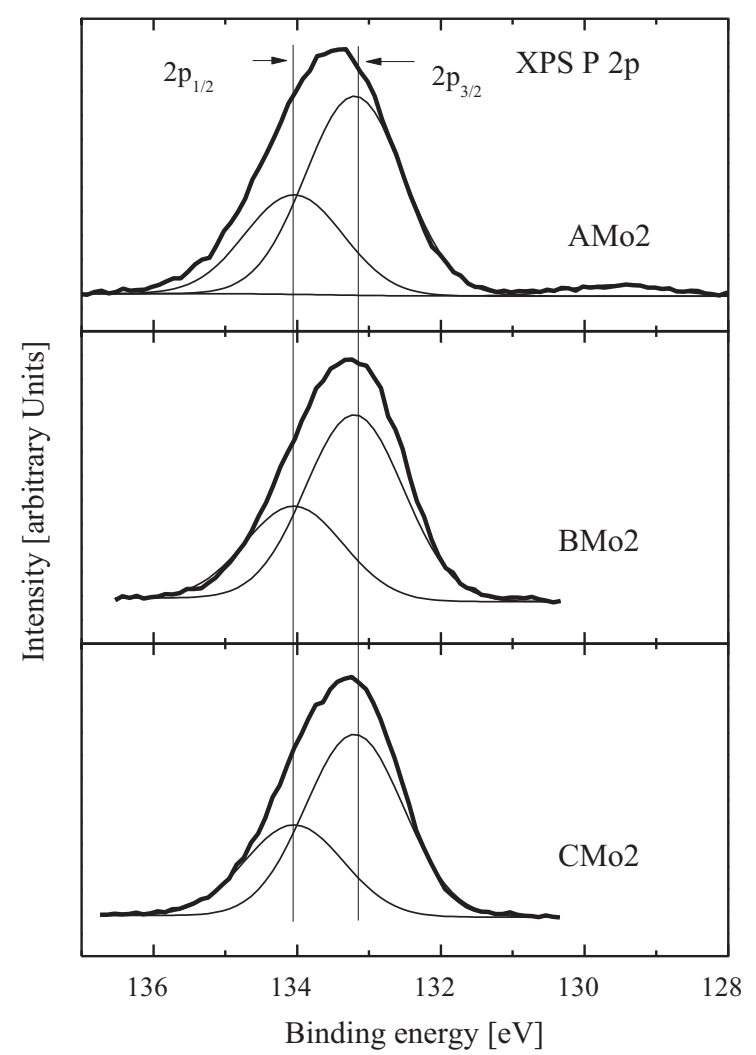

Fig. 7. The XPS P 2p spectra of AMo2, BMo4, and CMo4 samples after anodic oxidation.

for the surface of coarse-grained and nanostructured nitinol after etching the nitinol in hydrofluoric acid (HF 40\%, for $1 \mathrm{~min}$ ) [41].

The XRD patterns of the anodically oxidised AMo2, BMo4, and CMo2 sample surfaces are shown in Fig. 13. On the AMo2 and CMo2 surfaces, only one crystalline phase, titanium, is observed. This result suggests that the $\mathrm{TiO}_{2}$ layers that are formed during anodic oxidation are amorphous. On the BMo4 surface, titanium is still the prevalent phase; however, small anatase peaks can be

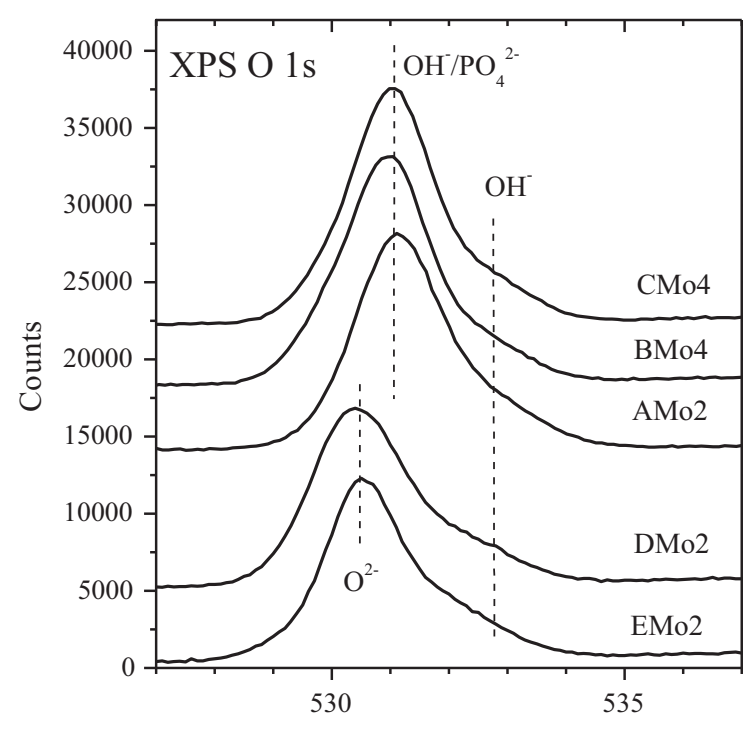

Binding Energy $[\mathrm{eV}]$

Fig. 8. The XPS O 1s spectra of Ti-Mo samples after anodic oxidation (AMo2 - A bath and $200 \mathrm{~V}, \mathrm{BMo} 4-\mathrm{B}$ bath and $400 \mathrm{~V} ; \mathrm{CMo} 4-\mathrm{C}$ bath and $400 \mathrm{~V}, \mathrm{DMo} 2-\mathrm{D}$ bath and $200 \mathrm{~V}, \mathrm{EMo} 2-\mathrm{E}$ bath and $200 \mathrm{~V})$. 


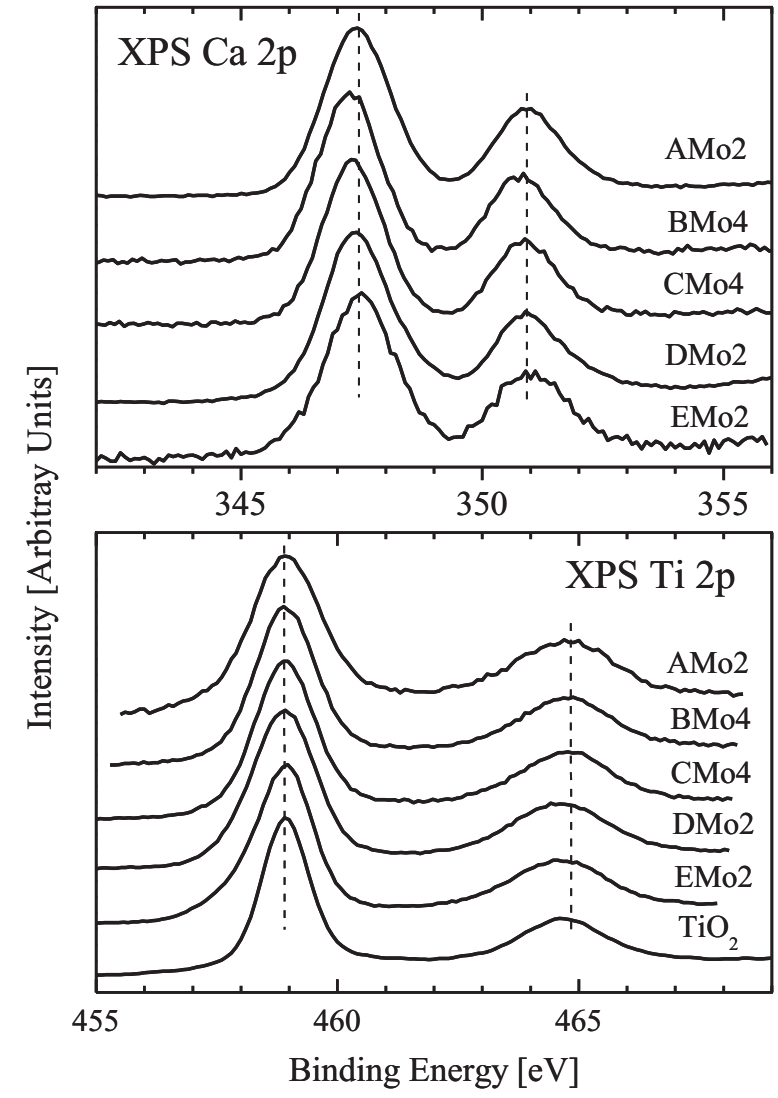

Fig. 9. The XPS Ca 2p and Ti 2p spectra of AMo2, BMo4, CMo4, DMo2 and EMo2 samples.

observed. These findings are confirmed by Raman spectroscopy. Typical Raman spectra taken from the AMo2, BMo4, and CMo2 sample surfaces are shown in Fig. 14. Based on ref. [42], crystalline anatase has six active Raman modes $\left(\mathrm{A}_{1 \mathrm{~g}}+2 \mathrm{~B}_{1 \mathrm{~g}}+3 \mathrm{E}_{\mathrm{g}}\right)$ located at $144\left(E_{g}\right), 197\left(E_{g}\right), 399\left(B_{1 g}\right), 513\left(A_{1 g}\right), 519\left(B_{1 g}\right)$, and $639\left(E_{g}\right) \mathrm{cm}^{-1}$, with the most intense mode at $144 \mathrm{~cm}^{-1}$. Rutile is characterised by four active Raman modes $\left(A_{1 g}, B_{1 g}, B_{2 g}, E_{g}\right)$ that are located at $143\left(B_{1 g}\right), 447\left(E_{g}\right), 612\left(A_{1 g}\right)$, and $826\left(B_{2 g}\right) \mathrm{cm}^{-1}[43,44]$, and the modes at 447 and $612 \mathrm{~cm}^{-1}$ have the two most intense peaks. All of the Raman spectra of the investigated anodic oxide layers exhibit similar features: broad peaks with relatively low intensities, which indicate that the $\mathrm{TiO}_{2}$ layers possess poor crystallinity. In the case of AMo2, BMO4, and CMo2 samples, we observed a peak at $144 \mathrm{~cm}^{-1}$

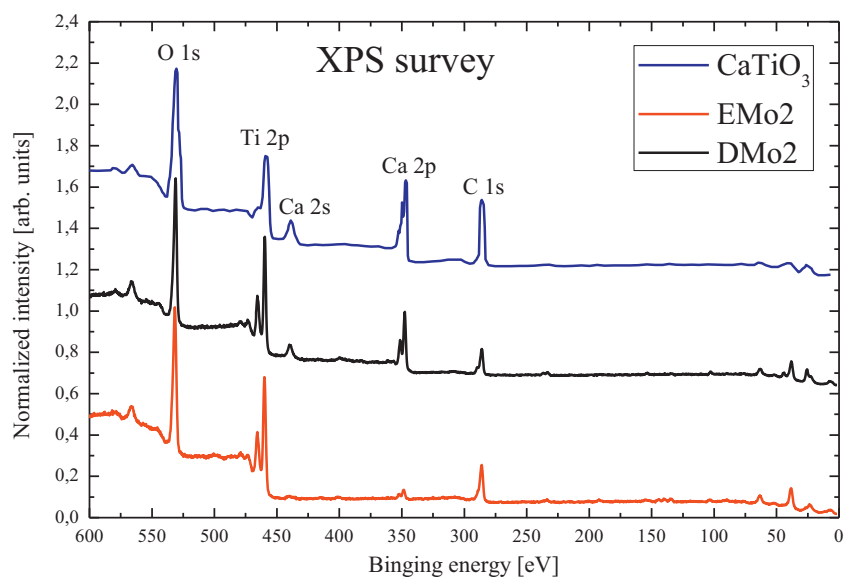

Fig. 10. The XPS survey spectra of DMo2, $\mathrm{EMo}_{2}$ and $\mathrm{CaTiO}_{3}$.

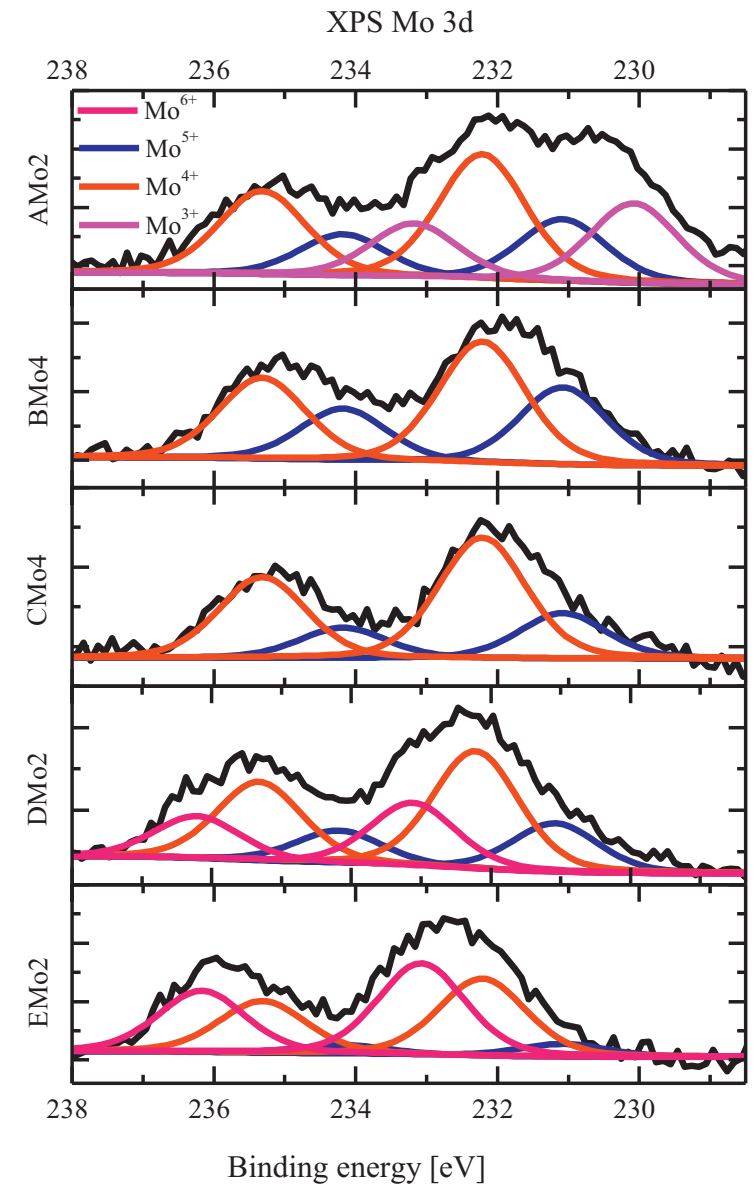

Fig. 11. The XPS Mo 3d spectra of $A M o 2, B M o 4, C M o 4$, DMo2 and EMo2 samples.

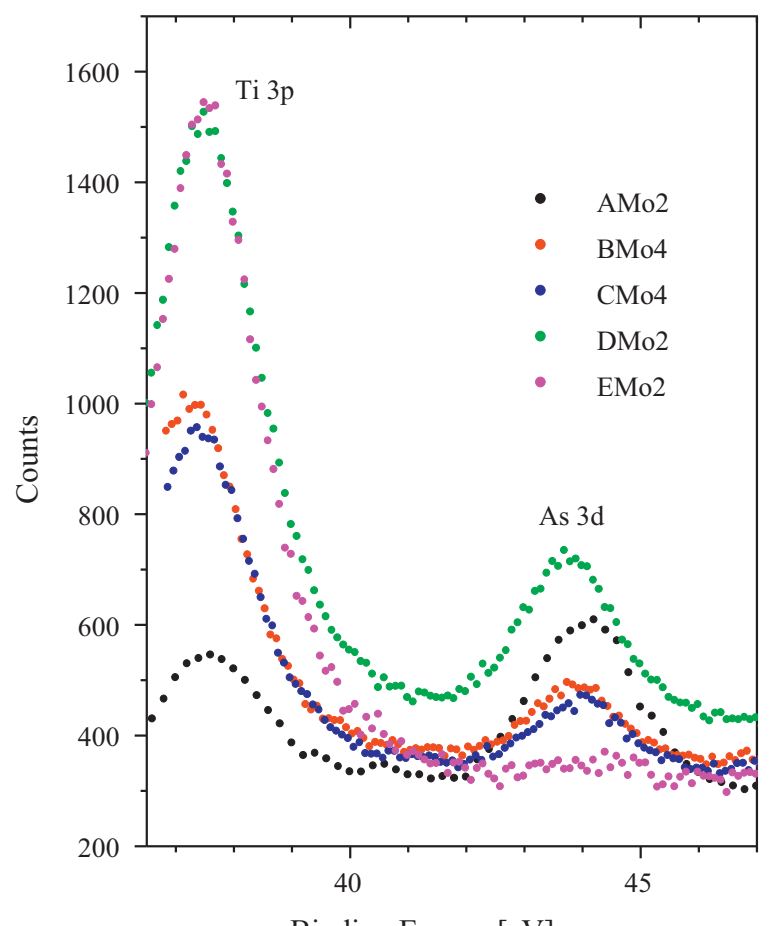

Binding Energy $[\mathrm{eV}]$

Fig. 12. The XPS As $3 \mathrm{~d}$ of Ti-Mo samples after anodic oxidation (AMo2 - A bath and $200 \mathrm{~V}, \mathrm{BMo} 4-\mathrm{B}$ bath and $400 \mathrm{~V} ; \mathrm{CMo} 4-\mathrm{C}$ bath and $400 \mathrm{~V}, \mathrm{DMo} 2-\mathrm{D}$ bath and $200 \mathrm{~V}$, EMo2 - E bath and 200 V). 


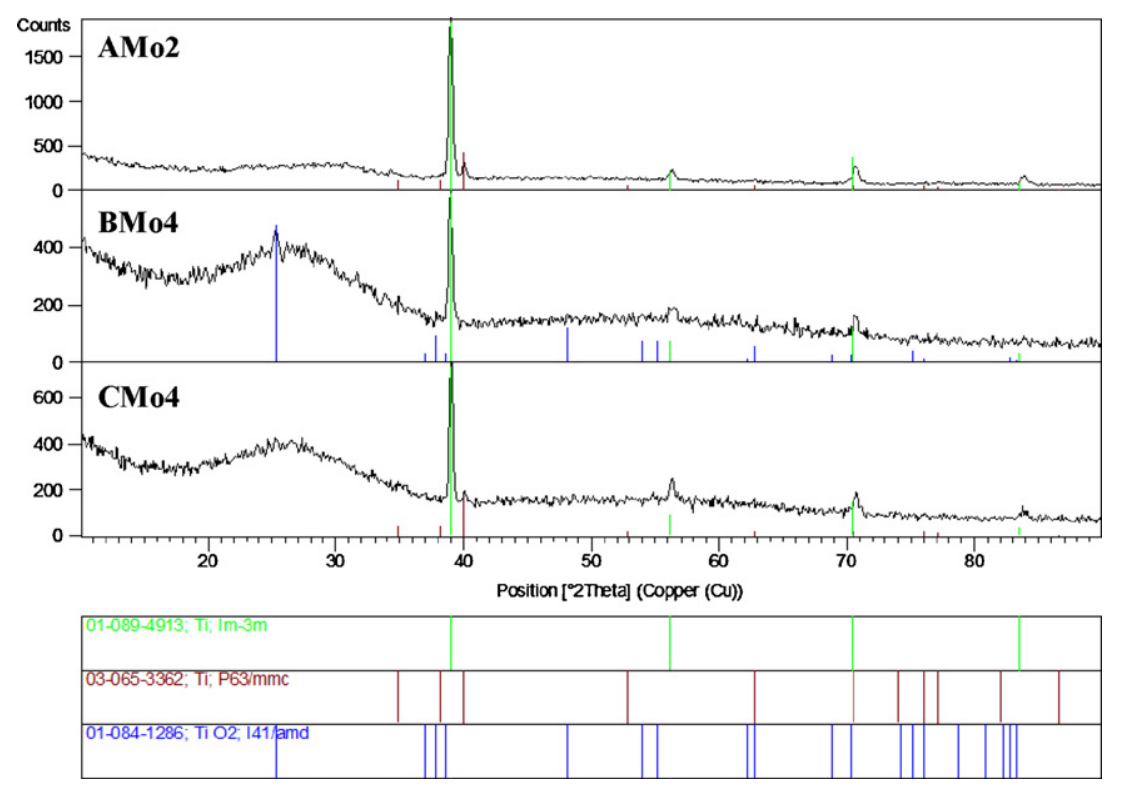

Fig. 13. The TL-XRD patterns of AMo2, BMo4, and CMo4 samples (AMo2 - A bath and $200 \mathrm{~V}$, BMo4 - B bath and $400 \mathrm{~V}$; CMo $4-\mathrm{C}$ bath and $400 \mathrm{~V}$ ).

that was assigned to the anatase phase of $\mathrm{TiO}_{2}$. However, that peak is most intense in the BMo4 sample. This result suggests that the crystallinity of the surface improved, which was already observed in the XRD study. The broad band observed near $960 \mathrm{~cm}^{-1}$ belongs to the $\nu 1$ phonon mode of the $\mathrm{P}-\mathrm{O}$ bond of the phosphate group, implying that phosphate is a surface species. For the electrolyte containing $\mathrm{Ca}\left(\mathrm{H}_{2} \mathrm{PO}_{2}\right)_{2}$, elements from the electrolyte were incorporated into the coatings, as shown in the EDX or XRF analysis, and the atomic ratios of $\mathrm{Ca} / \mathrm{P}$ are 0.5 for sample $\mathrm{A}, 0.2$ for sample $\mathrm{B}$, and 0.2 for sample $C$. However, the formed phosphates do not have a crystalline form.

The XRD of the sample surfaces anodised in $0.1 \mathrm{M}$ and $1 \mathrm{M}$ $(\mathrm{HCOO})_{2}$ Ca solutions are depicted in Fig. 15 . For the $0.1 \mathrm{M}$ solution, we observe crystalline phases of titanium, $\mathrm{CaTiO}_{3}$, and anatase. For the $1 \mathrm{M}$ solution, the XRD pattern of the $\mathrm{TiO}_{2}$ layer also shows rutile crystallites. Raman spectroscopy confirmed these results (Fig. 16); the peak at $144 \mathrm{~cm}^{-1}$ from anatase is well resolved for both sample surfaces. The enhancement of the relative intensity of the anatase band is observed with the increase in the $(\mathrm{HCOO})_{2} \mathrm{Ca}$ solution

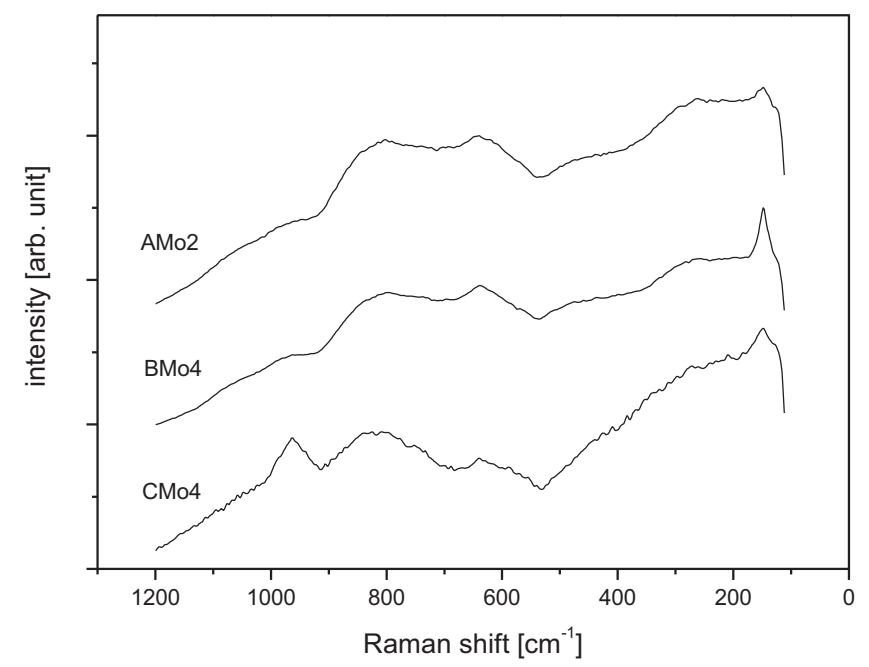

Fig. 14. Raman spectra of the surface of AMo2, BMo4, and CMo4 samples (AMo2 A bath and $200 \mathrm{~V}, \mathrm{BMo} 4-\mathrm{B}$ bath and $400 \mathrm{~V}$; CMo4 - C bath and $400 \mathrm{~V})$. concentration. Small peaks at approximately 447 and $612 \mathrm{~cm}^{-1}$ are also observed with this increase that are assigned to the rutile structure of $\mathrm{TiO}_{2}$. The XRD analysis indicates the presence of $\mathrm{Ti}_{1} \mathrm{TiO}_{2}$, and $\mathrm{CaTiO}_{3}$. Calcium titanate is regarded as a compound that enhances bone conductivity [45]. $\mathrm{CaTiO}_{3}$ does not form a bioactive film on the surface, but this layer promotes the formation of hydroxyapatite. A layer with a thickness of approximately $50 \mathrm{~nm}$ is enough to enhance bone conductivity [46]. Calcium titanate has been suggested as a material to provide a positive surface charge that would interact with the negatively charged phosphate ions in the fluid and induce the formation of a calcium phosphate layer. Additionally, calcium titanate has been reported as an intermediate for the biomimetic deposition of hydroxyapatite. Moreover, a $\mathrm{CaTiO}_{3}$ layer acts as a calcium reservoir [47-49]. $\mathrm{CaTiO}_{3}$ was obtained as reported in the literature [50,51] after an alkali treatment of the modified titanium alloys. After the alkali modification, a titania hydrogel layer containing basic Ti-OH groups is formed on the surface of the titanium coatings. Several papers reported that this layer would produce negatively charged hydrates on the surface of the titanium coatings after being immersed in a simulated body fluid [52,53]. This fluid helps to enhance calcium adsorption, leading to the formation of a $\mathrm{CaTiO}_{3}$-like structure.

The surface analysis showed that bioactive elements ( $\mathrm{Ca}$ and $\mathrm{P}$ or $\mathrm{Ca}$ ) from the examined electrolytes could be incorporated into the oxide layers. Depending on the applied voltage, the morphology of the oxidised surfaces of the Ti-15Mo alloy samples changed. Additionally, the chemical compositions of the surfaces changed. During PEO, the surface layer of the alloy is oxidised; not only is titanium oxidised into titania $\left(\mathrm{TiO}_{2}\right)$ but other alloying elements are oxidised. In the case of the AMo2 and $\mathrm{CMo} 4$ samples, titania is in an amorphous form - there is a characteristic "halo" in the XRD patterns. In the case of the other samples, titania is in one of its crystalline forms: anatase or rutile. This result could be due to the lower temperature used during PEO, which would not allow the phase transition. To facilitate osseointegration, calcium and phosphate ions should be incorporated into the surface layer. The use of many different analytical techniques confirmed the presence of the ions and their forms. In the examined samples, phosphorous in the form of phosphate ions exhibited structures similar to those of hydroxyapatite, but no crystalline forms were exhibited (AMo2, BMo4, and CMo4 samples). The XRD analysis indicated that calcium 


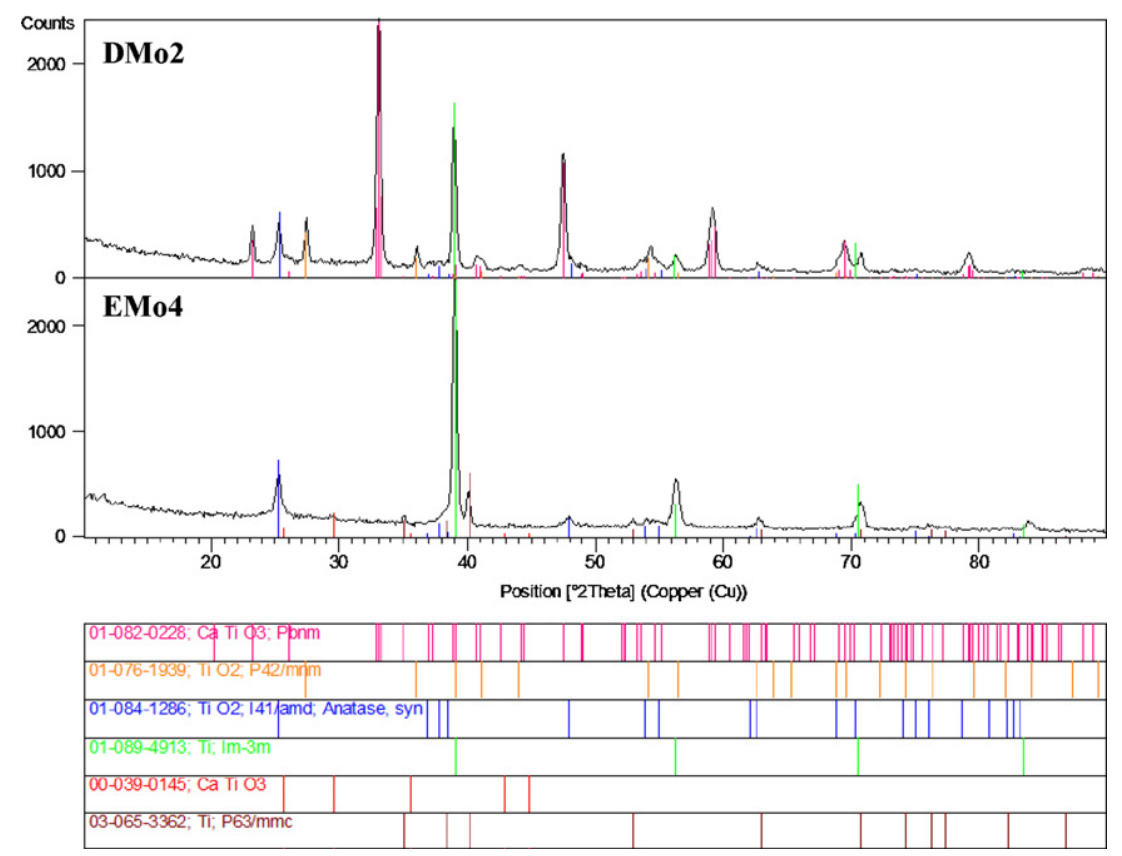

Fig. 15. The TL-XRD patterns of DMo2 and EMo2 samples (DMo2 - D bath and 200 V, EMo2 - E bath and 200 V).

occurs as calcium titanate (DMo4 and EMo4 samples). Despite the small amount of calcium incorporated into the layer of the EMo2 sample (XRF analysis), the XRD analysis was sensitive enough to determine the presence of $\mathrm{CaTiO}_{3}$.

\subsection{Electrochemical characteristics of selected samples in Ringer's solution}

The corrosion resistance of Ti-Mo alloys was studied using electrochemical and open-circuit analysis [25,54-56], and the results show that these alloys are more corrosion resistant than pure Ti. Open-circuit potential $\left(E_{\mathrm{OCP}}\right)$ measurements for the etched (Ti-15Mo) and anodised (AMo-EMo) samples were performed. For the samples, the $\mathrm{E}_{\mathrm{OCP}}$ curves as a function of time are presented in Fig. 17. The $E_{\mathrm{OCP}}$ for the AMo2 and BMo4 samples decreased after the anodising treatment. This effect on $E_{\mathrm{OCP}}$ may indicate certain sample activity in a physiological solution. These observations

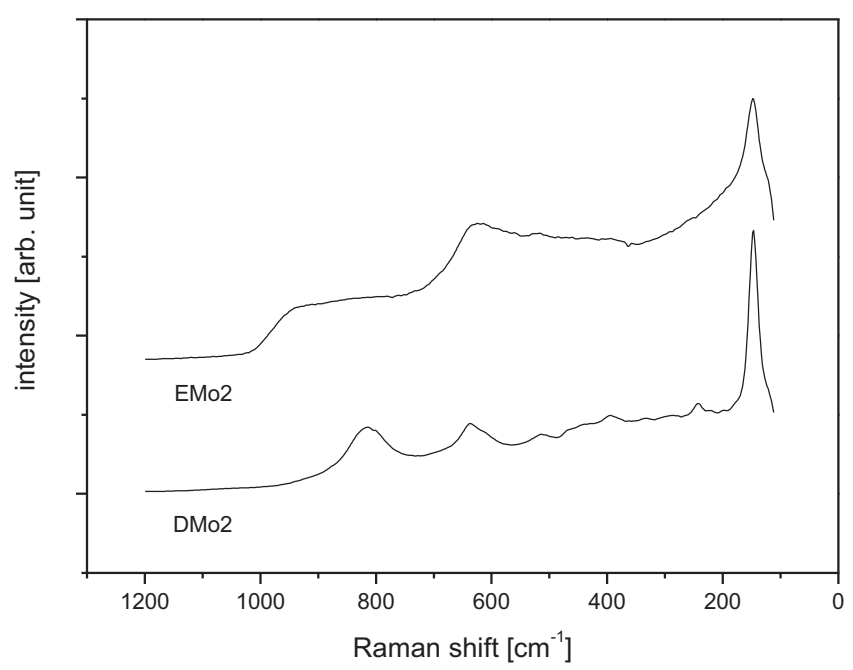

Fig. 16. Raman spectra of the surface of DMo2 and EMo2 samples (DMo2 - D bath and $200 \mathrm{~V}, \mathrm{EMo} 2-\mathrm{E}$ bath and $200 \mathrm{~V}$ ). may be due to a change in the crystallinity degree of the coating, to the conversion of anhydrous oxides to hydrated oxides, or to the unsealing of the coating [57]. The EOCP values of the CMo-EMo and $\mathrm{Ti}-15 \mathrm{Mo}$ samples increase over time. These results are typical for non-treated or oxidised titanium alloys in a chloride-containing medium, such as Ringer's solution [14,20]. The value of the recorded $E_{\mathrm{OCP}}$ potential for pure Ti-15Mo alloy (Table 5) agrees well with the value from ref. [25]. The $\mathrm{E}_{\mathrm{OCP}}$ for the examined samples after anodic oxidation is higher than the $E_{\mathrm{OCP}}$ of pure Ti-15Mo alloy (Table 5), which is associated with the formation of the anodic layer on the alloy. The CMo4 sample showed a distinctly higher $E_{\mathrm{OCP}}$ than the other Ti-15Mo alloy samples. The higher $E_{\mathrm{OCP}}$ is caused by the presence of a thicker oxide layer formed on the Ti-15Mo alloy during PEO.

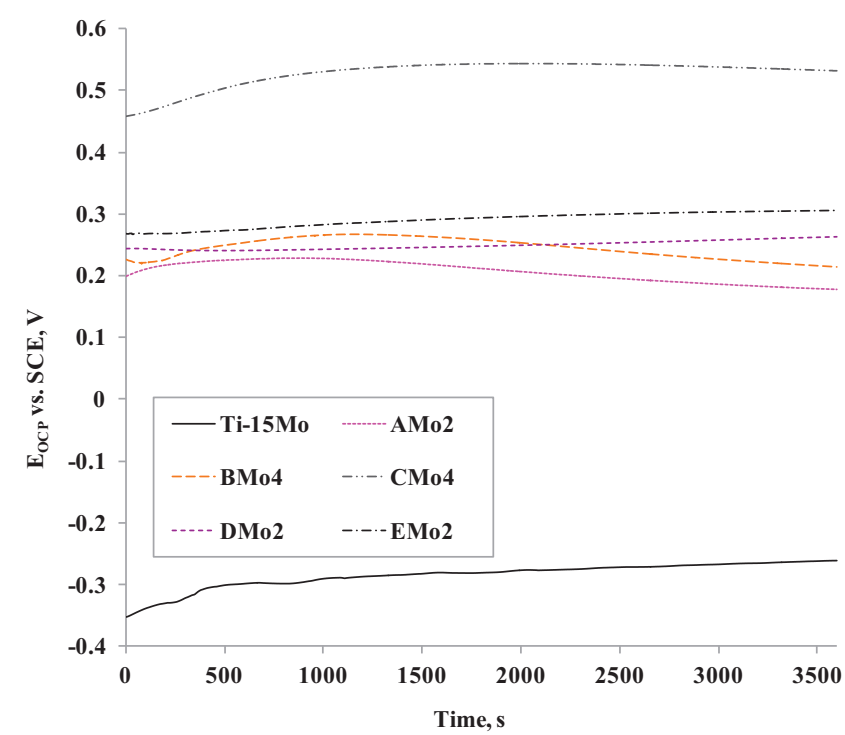

Fig. 17. The variation of the $E_{\mathrm{OCP}}$ with time for the etched Ti-15Mo alloy and Ti-15Mo alloy anodised at different conditions (AMo-EMo samples) in Ringer's solution. 
Table 5

The results of corrosion resistance investigations of the Ti-15Mo alloy in Ringer's solution.

\begin{tabular}{lllll}
\hline Sample & $E_{\mathrm{OCP}}, \mathrm{mV}$ & $E_{\mathrm{CORR}}, \mathrm{mV}$ & $j_{\mathrm{CORR}}, \mathrm{Acm}^{-2}$ & $\mathrm{Rp}, \Omega \mathrm{cm}^{2}$ \\
\hline Ti-15Mo & -262 & -321 & $4.352 \times 10^{-7}$ & $2.079 \times 10^{4}$ \\
AMo2 & 178 & 101 & $4.967 \times 10^{-8}$ & $3.291 \times 10^{5}$ \\
BMo4 & 215 & 125 & $3.695 \times 10^{-8}$ & $2.613 \times 10^{5}$ \\
CMo4 & 532 & 414 & $2.037 \times 10^{-7}$ & $5.038 \times 10^{4}$ \\
DMo2 & 263 & 130 & $2.967 \times 10^{-7}$ & $3.252 \times 10^{4}$ \\
EMo2 & 306 & 195 & $3.228 \times 10^{-8}$ & $1.347 \times 10^{6}$ \\
\hline
\end{tabular}

For the corrosion studies, the values of the corrosion potential determined using the potentiodynamic method are different from the $E_{\text {OCP }}$ values for all of the cases studied (Table 5). This behaviour is typical of titanium alloys in chloride solutions. These differences are explained by the depassivation phenomenon and by the chemical composition changes on the surface during the cathodic scanning that are due to the potentiodynamic tests beginning at a potential of $E_{\mathrm{OCP}}-200 \mathrm{mV}$, which decrease the $E_{\mathrm{OCP}}$ values with respect to the corrosion potential [58]. The results from the potentiodynamic measurements are presented in Fig. 18 and Table 5. These results clearly indicate that the anodic oxidation of the Ti-15Mo alloy causes a significant change in the corrosion resistance. The etched Ti-15Mo sample is characterised by a corrosion potential of $-0.321 \mathrm{~V}$, a corrosion current density of $43.5 \mathrm{nA} \mathrm{cm}^{-2}$, and a polarisation resistance of $20 \mathrm{k} \Omega \mathrm{cm}^{2}$. For the other samples, the values of the corrosion potential are significantly higher than that of the pure alloy. Moreover, the corrosion current densities of the AMo-EMo samples are lower than that of the pure Ti-15Mo alloy (Fig. 18), and the polarisation resistances are higher (Table 5). A dense barrier layer with a thickness of 500-750 nm at the PEO coating/Ti-15Mo interface plays an important role in the corrosion properties of the coated samples. This barrier layer can be observed in Fig. 3. Moreover, this thick coating, which has a high hardness and elastic modulus, is relatively brittle, which could result in the presence of several cracks [28]. Thus, $\mathrm{Cl}^{-}$ions in the $\mathrm{NaCl}$ solution can easily penetrate into the coating via these cracks. A suitable coating thickness should be selected to obtain anticorrosion coatings on a Ti-15Mo alloy via the PEO process. The anodisation process at a voltage of $200 \mathrm{~V}$ in the E bath significantly improved the anticorrosion properties (EMo2 sample). The corrosion potential increased to $0.195 \mathrm{~V}$, and the corrosion current density decreased to $32 \mathrm{nAcm}^{-2}$.

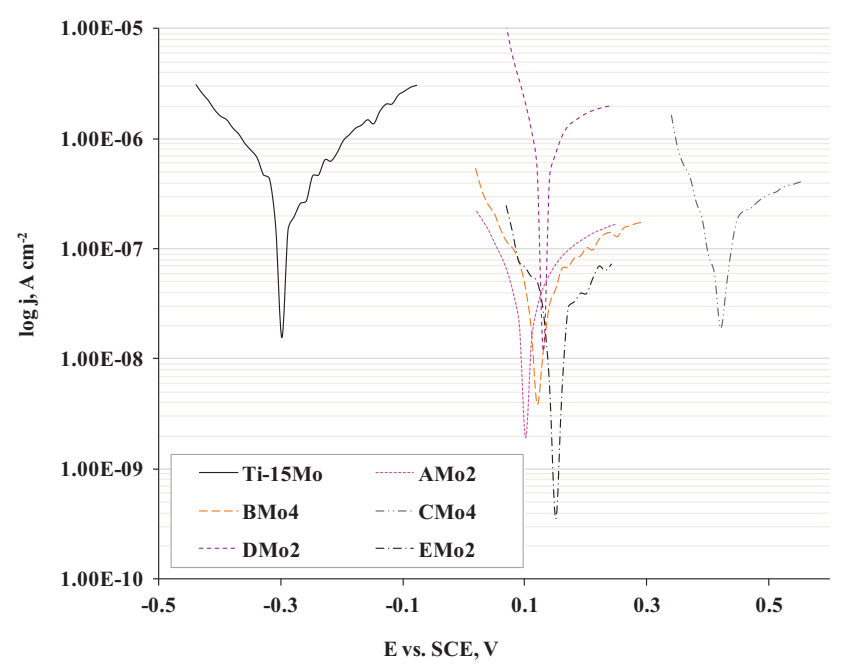

Fig. 18. The polarisation curves recorded for the etched Ti-15Mo alloy and Ti-15Mo alloy anodised at different conditions (AMo-EMo samples).
During CV measurements, low current densities of the anodised samples (AMo-EMo) were observed (CV not shown), which indicate the excellent stability and corrosion resistance of the Ti-15Mo alloy. Moreover, no pitting (anodic breakdown) was observed for the samples in the studied potential range. During the reverse scan, the current falls to values near zero and remains there until the scan is completed, without any evidence of reduction in the previously grown oxide [54]. Similar behaviour was obtained by Simka [20] for Ti-13Nb-13Zr in Ringer's solution; no pit corrosion was observed. Yu and Scully [59] reported that a Ti-13Nb-13Zr alloy exhibits a pit potential larger than $22.8 \mathrm{~V}$ (SCE) in deaerated lactated Ringer's solution. Conversely, Oliveira et al. [60,61] found that a Ti-50Zr alloy exhibits pitting corrosion processes in Ringer's solution, suggesting that the addition of $\mathrm{Zr}$ to Ti promoted pitting corrosion. A similar behaviour was exhibited for pure zirconium; corrosion resistance investigations are presented in ref. [57].

\section{Conclusions}

This work presents a preliminary study on the incorporation of calcium and phosphorus or of calcium only into an oxide film on a Ti-15Mo alloy via the anodic oxidation method. The process was performed in a bath containing $\mathrm{H}_{3} \mathrm{PO}_{4}, \mathrm{Ca}\left(\mathrm{H}_{2} \mathrm{PO}_{2}\right)_{2}$, or $(\mathrm{HCOO})_{2} \mathrm{Ca}$. The incorporation of $\mathrm{Ca}$ and $\mathrm{P}$ occurred after the application of a voltage higher than the breakdown voltage of the oxide layer. The results showed that anodisation improved the corrosion resistance of the Ti-15Mo alloy in Ringer's solution. The largest increase in the resistance was observed after oxidation of the alloy at $200 \mathrm{~V}$ in the E bath, i.e., after the formation of a compact oxide layer. Electrochemical investigations indicated that some of the specimens that were oxidised at higher voltages can be electrochemically active. Such behaviour can promote the adsorption of specific ions following the crystallisation of hydroxyapatite in a tissue environment. The results of this research suggest that the formation of an oxide layer enriched with calcium and phosphorus will contribute to an increased Ti-15Mo bioactivity. The produced oxide layers require biological investigations, the results of which will be presented in the future.

\section{Acknowledgements}

We acknowledge the support of the Ural Division of the Russian Academy of Sciences (Project 12-T-2-1009) and the Russian Foundation for Basic Research (Project 13-08-96007).

\section{References}

[1] M. Metikoš-Huković, A. Kwokal, J. Piljac, The influence of niobium and vanadium on passivity of titanium-based implants in physiological solution, Biomaterials 24 (2003) 3765.

[2] M. Long, H.J. Rack, Titanium alloys in total joint replacement - a materials science perspective, Biomaterials 19 (1998) 1621.

[3] K. Bordji, J.Y.Jouzeau, D. Mainard, E. Payan, P. Netter, K.T. Rie, T. Stucky, M. HageAli, Cytocompatibility of Ti-6Al-4V and Ti-5Al-2.5Fe alloys according to three surface treatments, using human fibroblasts and osteoblasts, Biomaterials 17 (1996) 926.

[4] S. Bruni, M. Martinesi, M. Stio, C. Treves, T. Bacci, F. Borgioli, Effects of surface treatment of Ti-6Al-4V titanium alloy on biocompatibility in cultured human umbilical vein enodthelial cells, Acta Biomaterialia 1 (2005) 223.

[5] M. Geetha, A.K. Sing, R. Asokamani, A.K. Gogia, Ti based biomaterials, the ultimate choice for orthopaedic implants - a review, Progress in Materials Science 54 (2009) 397.

[6] M. Nawarro, A. Michiardi, O. Castano, J.A. Planell, Biomaterials in orthopaedic, Journal of the Royal Society Interaface 5 (2008) 1137.

[7] Y.L. Zhou, D.M. Luo, Microstructures and mechanical properties of Ti-Mo alloys cold-rolled and heat treated, Materials Characterization 62 (2011) 931.

[8] N.T.C. Oliveira, G. Alexio, R. Caram, A.C. Guastaldi, Development of Ti-Mo alloys for biomedical applications: microstructure and electrochemical characterization, Materials Science and Engineering A 452-453 (2007) 727.

[9] W.F. Ho, C.P. Ju, J.H. Chern Lin, Structure and properties of cast binary Ti-Mo alloys, Biomaterials 20 (1999) 2115. 
[10] Y. Zhang, T. Fu, Y. Han, Q. Wang, Y. Zhao, K. Xu, In vitro and in vivo tests of hydrothermally synthesised hydroxyapatite coating, Biomolecular Engineering 19 (2002) 57

[11] C. Chang, J. Huang, J. Xia, C. Ding, Study on crystallization kinetics of plasma sprayed hydroxyapatite coating, Ceramics International 25 (1999) 479.

[12] M. Sato, E. Slamovich, T. Webster, Enhanced osteoblast adhesion on hydrothermally treated hydroxyapatite/titania/poly(lactide-co-glycolide) sol-gel titanium coatings, Biomaterials 26 (2005) 1349.

[13] K. Hamada, M. Kon, T. Hanawa, K. Yokoyama, Y. Miyamoto, K. Asaoka, Hydrothermal modification of titanium surface in calcium solutions, Biomaterials 23 (2002) 2265.

[14] W. Simka, A. Iwaniak, G. Nawrat, A. Maciej, J. Michalska, K. Radwanski, J. Gazdowicz, Modification of titanium oxide layer by calcium and phosphorus, Electrochimica Acta 54 (2009) 6983.

[15] T.H. The, A. Berjabu, S. Mato, P. Skeldon, G.E. Thompson, H. Habazaki, K. Shimizu, Initial stages of plasma electrolytic oxidation of titanium, Corrosion Science 45 (2003) 2757

[16] L. Le Gu'ehennec, A. Soueidan, P. Layrolle, A. Amouri, Surface treatments of titanium dental implants for rapid osseointegration, Dental Materials 23 (2007) 844.

[17] H.J. Robinson, A.E. Markaki, C.A. Collie, T.W. Clone, Cell adhesion to plasma electrolytic oxidation (PEO) titania coatings, assessed using a centrifuging technique, Journal of the Mechanical Behavior of Biomedical Materials 4 (2011) 2103.

[18] E. Matykina, R. Arrabal, P. Skeldon, G.E. Thompson, Transmission electron microscopy of coatings formed by plasma electrolytic oxidation of titanium, Acta Biomaterialia 5 (2009) 1356.

[19] M. Shokouhfar, C. Dehghanian, A. Baradaran, Preparation of ceramic coating on Ti substrate by plasma electrolytic oxidation in different electrolytes and evaluation of its corrosion resistance, Applied Surface Science 257 (2011) 2617.

[20] W. Simka, Preliminary investigations on the anodic oxidation of Ti-13Nb-13Z alloy in a solution containing calcium and phosphorus, Electrochimica Acta 56 (2011) 9831.

[21] B. Yang, M. Uchida, H.M. Kim, X. Zhang, T. Kokubo, Preparation of bioactive titanium metal via anodic oxidation treatment, Biomaterials 25 (2004) 1003.

[22] T. Goryczka, G. Dercz, K. Prusik, L. Pająk, E. Łągiewka, Crystallite size determination of $\mathrm{MgO}$ nanopowder from X-ray diffraction patterns registered in GIXD technique, Solid State Phenomena 163 (2010) 177.

[23] T. Goryczka, G. Dercz, L. Pająk, E. Łągiewka, Lattice and peak profile parameters in GIXD technique, Solid State Phenomena 130 (2007) 281.

[24] EN ISO 4287:1997 standard: Geometrical product specification (GPS) Surface texture: Profile methods - Terms, definitions and surface texture parameters.

[25] M. Karthega, V. Raman, N. Rajendran, Influence of potential on the electrochemical behaviour of $\beta$ titanium alloys in Hank's solution, Acta Biomaterialia 3 (2007) 1019.

[26] E. Matykina, R. Arrabal, P. Skeldon, G.E. Thompson, P. Wang, P. Wood, Plasma electrolytic oxidation of a zirconium alloy uder AC conditions, Surface and Coatings Technology 204 (2010) 2142.

[27] J.Y. Ha, Y. Tsutsumi, H. Doi, N. Nomura, K.H. Kim, T. Hanawa, Plasma electrolytic oxidation of a zirconium alloy under AC conditions, Surface and Coatings Technology 205 (2011) 4948.

[28] W. Xue, Q. Zhu, Q. Jin, M. Hua, Characterization of ceramic coatings fabricated on zirconium alloy by plasma electrolytic oxidation in silicate electrolyte, Materials Chemistry and Physics 120 (2010) 656.

[29] Z.X. Chen, W.X. Wang, Y. Takao, T. Mastubara, L.M. Ren, Microstucture and shear fracture characteristics of porous anodic $\mathrm{TiO}_{2}$ layer before and after heat treatment, Applied Surface Science 257 (2011) 7254

[30] H.J. Oh, J.H. Lee, Y. Jeong, Y.J. Kim, C.S. Chi, Microstructural characterization of biomedical titanium oxide film fabricated by electrochemical method, Surface and Coatings Technology 198 (2005) 247.

[31] W. Simka, A. Sadkowski, M. Warczak, A. Iwaniak, G. Dercz, J. Michalska, A. Maciej, Characterization of passive films formed on titanium during anodic oxidation, Electrochimica Acta 56 (2011) 8962.

[32] D. Krupa, J. Baszkiewicz, J. Zdunek, J. Smolik, Z. Słomka, J.W. Sobczak, Characterization of the surface layers formed on titanium by plasma electrolytic oxidation, Surface and Coatings Technology 205 (2010) 1743.

[33] L. Calderín, M.J. Stott, A. Rubio, Electronic and crystallographic structure of apatites, Physical Review B 67 (2003) 134106

[34] E. Krasicka-Cydzik, K. Kowalski, I. Glazowska, Electrochemical formation of bioactive surface layer on titanium, Journal of Achievements in Materials and Manufacturing Engineering 18 (2006) 147.

[35] M.A. Baker, S.L. Assis, O.Z. Higa, I. Costa, Nanocomposite hydroxyapatite formation on a Ti-13Nb-13Zr alloy exposed in a MEM cell culture mediumand the effect of $\mathrm{H}_{2} \mathrm{O}_{2}$ addition, Acta Biomaterialia 5 (2009) 63.
[36] John F. Moulder, William F. Stickle, Peter E. Sobol, Kenneth D, Handbook of X ray Photoelectron Spectroscopy. Bomben, ULVAC-PHI, Inc., 370 Enzo, Chigasaki 253-8522, Japan, 1995.

[37] S. Tan, P. Yang, C. Li, W. Wang, J. Wang, M. Zhang, X. Jing, et al., Preparation, characterization and luminescent properties of spherical $\mathrm{CaTiO}_{3}: \mathrm{Pr}^{3+}$ phosphors by spray pyrolysis, Solid State Sciences 12 (2010) 624.

[38] I. Fernández-Olmo, J.L. Fernández, A. Irabien, Purification of dilute hydrofluoric acid by commercial ion exchange resins, Technology 56 (Sep) (2007) 118.

[39] T. Fujita, G. Dodbiba, H.S. Park, K. Higashino, S. Matsuo, Arsenic removal in lowgrade fluorite by using mineral processing techniques, Resources Processing 57 (2010) 105.

[40] Merck Chemicals Available at: http://www.merck-chemicals.com, (accessed 12.12.11)

[41] D.M. Korotin, S. Bartkowski, E.Z. Kurmaev, C. Borchers, M. Muëller, M. Neumann, D.V. Gunderov, R.Z. Valiev, S.O. Cholakh, Arsenic contamination of coarsegrained and nanostructured nitinol surfaces induced by chemical treatment in hydrofluoric acid, Journal of Biomedical Materials Research B: Applied Biomaterials 100B (2012) 1812.

[42] M. Giarola, A. Sanson, F. Monti, G. Mariotto, M. Bettinelli, A. Speghini, G. Salviulo Vibrational dynamics of anatase $\mathrm{TiO}_{2}$ : polarized Raman spectroscopy and ab initio calculations, Physical Review B 81 (2010) 174305.

[43] V.Swamy, A. Kuznetsov, L.S. Dubrovinsky, R.A. Caruso, D.G. Shchukin, B.C. Muddle, Finite-size and pressure effects on the Raman spectrum of nanocrystalline anatase $\mathrm{TiO}_{2}$, Physical Review B 71 (2005) 184302.

[44] F.D. Hardcastle, H. Ishihara, R. Sharma, A.S. Biris, Photoelectroactivity, Raman spectroscopy of anodized titania $\left(\mathrm{TiO}_{2}\right)$ photoactive water-splitting catalysts as a function of oxygen-annealing temperature, Journal of Materials Chemistry 21 (2011) 6337.

[45] M. Manso, M. Langlet, J.M. Martinez-Duart, Testing sol-gel $\mathrm{CaTiO}_{3}$ coatings for biocompatible applications, Materials Science and Engineering C 23 (2003) 447.

[46] N. Ohtsu, K. Saito, K. Asami, T. Hanawa, Characterization of $\mathrm{CaTiO}_{3}$ thin film prepared by ion-beam assisted deposition, Surface and Coatings Technology 200 (2006) 5455

[47] J.P. Wiff, V.M. Fuenzalida, J.L. Arias, M.S. Fernandez, Hydrothermal-electrochemical $\mathrm{CaTiO}_{3}$ coatings as precursor of a biomimetic calcium phosphate layer, Materials Letters 61 (2007) 2739.

[48] J.W. Park, Y. Tustusmi, C.S. Lee, C.H. Park, Y.J. Kim, J.H. Jang, D. Khang, Y.M. Im, H. Doi, N. Nomura, T. Hanawa, Surface structures and osteoblast response of hydrothermally produced $\mathrm{CaTiO}_{3}$ thin film on $\mathrm{Ti}-13 \mathrm{Nb}-13 \mathrm{Zr}$ alloy, Applied Surface Science 257 (2011) 7856.

[49] S. Holliday, A. Stanishevsky, Crystallization of $\mathrm{CaTiO}_{3}$ by sol-gel synthesis and rapid thermal processing, Surface and Coatings Technology 188-189 (2004) 741.

[50] N. Sugiyama, H.Y. Xu, T. Onoki, Y. Hoshikawa, T. Watanabe, N. Matsushita, X Wang, F.X. Qin, M. Fukuhara, M. Tsukamoto, N. Abe, Y. Komizo, A. Inoue, M. Yoshimura, Bioactive titanate nanomesh layer on the Ti-based bulk metallic glass by hydrothermal-electrochemical technique, Acta Biomaterialia 5 (2009) 1367.

[51] X. Lu, Y. Leng, TEM study of calcium phosphate precipitation on bioactive titanium surfaces, Biomaterials 25 (2004) 1779.

[52] T. Kokubo, H.M. Kim, M. Kawashita, Novel bioactive materials with different mechanical properties, Biomaterials 24 (2003) 2161.

[53] T. Himeno, M. Kawashita, H.M. Kim, T. Kokubo, T. Nakamura, Zeta-potential variation of bioactive titanium metal during apatite formation on its surface in simulated body fluid, in: S. Brown, I.R. Clarke, P. Williams (Eds.), Bioceramics, vol. 14, Trans Tech Publishers, Switzerland, 2001, p. 641.

[54] N.T.C. Oliveira, A.C. Guastaldi, Electrochemical behavior of Ti-Mo alloys applied as biomaterial, Corrosion Science 50 (2008) 938.

[55] S. Kumar, T.S.N.S. Narayanan, Electrochemical characterization of $\beta$-Ti alloy in Ringer's solution for implant application, Journal of Alloys and Compounds 479 (2009) 699.

[56] S. Kumar, T.S.N.S. Narayanan, Corrosion behaviour of Ti-15Mo alloy for denta implant applications, Journal of Dentistry 36 (2008) 500.

[57] W. Simka, M. Sowa, R.P. Socha, A. Maciej, J. Michalska, Anodic oxidation of zirconium in silicate solutions, Electrochimica Acta (2012), http://dx.doi.org/10.1016/j.electacta.2012.10.130

[58] D. Mareci, R. Chelariu, D.M. Gordin, G. Ungureanu, T. Gloriant, Acta Biomaterialia 5 (2009) 3625

[59] S.Y. Yu, J.R. Scully, Corrosion and passivity of Ti-13\%Nb-13\%Zr in comparison to other biomedical implant alloys, Corrosion 53 (1997) 965.

[60] N.T.C. Oliveira, E.A. Ferreira, L.T. Duarte, S.R. Biaggio, R.C. Rocha-Filho, N. Bocchi, Corrosion resistance of anodic oxides on the Ti-50Zr and Ti-13Nb-13Zr alloys, Electrochimica Acta 51 (10) (2006) 2068.

[61] N.T.C. Oliveira, S.R. Biaggio, R.C. Rocha-Filho, N. Bocchi, Electrochemical studies on zirconium and its biocompatible alloys $\mathrm{Ti}-50 \mathrm{Zr}$ at.\% and $\mathrm{Zr}-2.5 \mathrm{Nb}$ wt.\% in simulated physiologic media, Journal of Biomedical Materials Research A 74A (2005) 397. 